\title{
Numerical simulation of the effect of water admixtures on the evolution of a helium/dry air discharge
}

\author{
C Lazarou ${ }^{1,2}$, A S Chiper ${ }^{3}$, C Anastassiou ${ }^{2}$, I Topala ${ }^{3}$, I Mihaila ${ }^{4}$, V Pohoata $^{3}$ and G E \\ Georghiou $^{1,2}$ \\ ${ }^{1}$ FOSS Research Centre for Sustainable Energy, Department of Electrical and Computer \\ Engineering, University of Cyprus, Nicosia, 1678, Cyprus \\ ${ }^{2}$ ENAL Electromagnetics and Novel Applications Lab, Department of Electrical and \\ Computer Engineering, University of Cyprus, Nicosia, 1678, Cyprus \\ ${ }^{3}$ Iasi Plasma Advanced Research Center (IPARC), Faculty of Physics, Alexandru Ioan Cuza \\ University of Iasi, Iasi 700506, Romania \\ ${ }^{4}$ Integrated Center of Environmental Science Studies in the North-Eastern Development \\ Region (CERNESIM), Alexandru Ioan Cuza University of Iasi, Iasi 700506, Romania
}

Corresponding authors: lazarou.constantinos@ucy.ac.cy, alina.chiper@uaic.ro and ionut.topala@uaic.ro

\begin{abstract}
In this study, a one-dimensional plasma fluid model is used to shed light into the evolution of a He/dry air (500 ppm, 79\% $\mathrm{N}_{2}$ and $21 \% \mathrm{O}_{2}$ ) dielectric barrier discharge (DBD) under different levels of water admixtures (20 to $2000 \mathrm{ppm}$ ). The model considers the analytical chemistry between helium, nitrogen, oxygen and water species and it is verified with experimental results to ensure its correctness. The simulation results show that water admixtures highly affect the discharge characteristics and the dominant ions in the mixture. In particular, it was observed that the increase of water in the mixture up to $600 \mathrm{ppm}$ causes the reduction of the breakdown voltage, while above $600 \mathrm{ppm}$ the breakdown voltage increases. Furthermore, the simulation results show that the most important positive ion in the mixture is $\mathrm{H}_{2} \mathrm{O}^{+}$for $20-100$ ppm of water admixtures and $\mathrm{H}_{11} \mathrm{O}_{5}{ }^{+}$for $100-2000 \mathrm{ppm}$ of admixtures. The most abundant negative charged species is found to be electrons for the range of water admixtures considered in this study. To interpret these results and to get an insight into the discharge evolution the main reaction pathways of ion production are investigated and analyzed.
\end{abstract}

\section{Introduction}

Atmospheric pressure plasma sources have received much attention in the last decades, due to low production cost, easy implementation and applications ranging from surface modification [1,2], plasma medicine [3,4], sterilization [5,6] etc. For applications used in temperature-sensitive materials, plasma sources usually operate with inert gases such as argon [7,8], neon [9-11] or helium [12-15], and their electrodes are covered with dielectric layers in order to prevent arcs $[16,17]$. The inert gases require low power, remain at low temperatures yet are still able to produce a wide range of excited and reactive species.

Helium dielectric barrier discharges (DBD) at atmospheric pressure have shown very promising results in the mentioned applications and particularly in biomedical applications, such as wound healing [18], treatment of cancer [19], bacterial inactivation etc. [6]. In such discharges the presence of water impurities is unavoidable and has been shown to highly affect the plasma chemistry and dynamic evolution [20-33]. In practice, water impurities are due to the operation of the plasma in the ambient humid air and also due to the plasma interaction with biotic surfaces in wet and moist environments. The significant effect of the impurities on the ion composition of a helium atmospheric pressure discharge is presented by Große-Kreul et al. [33]. In particular in this work, the ions composition in the mixture is investigated through mass spectrometry, with and without considering any purification methods. It was observed that without any purification methods the most important ion in the mixture are the water clusters $\mathrm{H}^{+}\left(\mathrm{H}_{2} \mathrm{O}\right)_{n}$. On the other hand, with purification methods, the ion composition is still affected 
by the residual trace gases. Furthermore, the presence of the water vapours into the gas discharge increases the removal efficiency of the volatile organic compounds as shown by Chiper et al [34]. As the discharge evolution is mainly determined by the ions, understanding the effect of the water admixtures on the ion composition is a prerequisite for effective utilization of these devices.

Due to the very complex chemistry behind this type of discharges (dozens of species and hundreds to thousands of reaction channels), mainly zero dimensional global models are used for these simulations. These models are computationally efficient, but have limitations, as they do not consider the spatial evolution (diffusion and convective transport) of the different species in the mixture. The effect of water admixtures on helium discharges through global models has been investigated by several researchers [35-40]. Particularly, Liu et al. [38] investigated the plasma chemistry of a $\mathrm{He} / \mathrm{H}_{2} \mathrm{O}$ mixture. The main species and dominant reaction pathways over a wide range of water admixtures $(0-3000 \mathrm{ppm})$ were highlighted. The simulation results showed that water charged species dominate over helium charged species for levels of water admixtures above $30 \mathrm{ppm}$. It was shown that the electronegativity of the discharge increases as the level of water increases in the helium mixture. In addition, Liu et al. [39] investigated the effect of $\mathrm{H}_{2} \mathrm{O}$ admixtures on the chemistry of a $\mathrm{He}+\mathrm{O}_{2}$ plasma. It was observed that even at low concentrations of water in the mixture, hydrated ions are abundant. In that study, the ratio between water and oxygen was kept constant at $0.5 \%$. It was found that the ratio $\mathrm{H}_{2} \mathrm{O} / \mathrm{O}_{2}$ of around one provides the highest amount of reactive species in the mixture. The effect of humid air on the plasma composition of a $\mathrm{He}+\mathrm{O}_{2}(0.5 \%)$ plasma was investigated by Murakami et al. [35-37]. It was found that as the level of humid air increases in the mixture, the electronegativity of the plasma composition increases while the concentration of reactive oxygen species decreases. Recently, through a global model, Schröter et al. [40] showed the importance of the surface reaction probabilities (for the species $\mathrm{H}, \mathrm{O}$ and $\mathrm{OH}$ ) and the reactor geometry on the composition of the reactive species in the mixture for a $\mathrm{He}+\mathrm{H}_{2} \mathrm{O}$ plasma. It was observed that the surface reaction probabilities especially for low mass species (such as $\mathrm{H}$ ) influence significantly the concentration levels of the reactive species in the mixture. It was also found that as the size of the reactor cross section increases, the densities of $\mathrm{H}, \mathrm{O}$ and $\mathrm{OH}$ increase with $\mathrm{H}$ experiencing the most dramatic increase due to its high diffusion and therefore lower surface losses.

As shown by global models, even at low levels of water admixtures in the helium plasma, the hydrated ions become dominant. However, hydration changes the mass of ions and consequently their transport coefficients. Global models cannot capture this effect on the plasma dynamics. In this study, a one-dimensional plasma fluid model is developed for the description of helium DBD in the presence of air admixtures (nitrogen, oxygen and water species). The model considers 56 species and 496 reaction channels and it is verified with experimental results in order to ensure its correctness. Subsequently, the level of dry air (79\% $\mathrm{N}_{2}$ and $21 \% \mathrm{O}_{2}$ ) is kept constant at $500 \mathrm{ppm}$ (a plausible value for atmospheric pressure discharges without any vacuum equipment) and the effect of water admixtures (20 to 2000 $\mathrm{ppm}$ ) on the discharge evolution is investigated. The simulation results show that the level of water in the mixture significantly affects the plasma chemistry, the discharge characteristics, and the concentration of ion species in the mixture. Hence, it is very important to understand these effects, in order to be able to optimize helium DBDs for specific applications.

The paper is organized as follows. The experimental setup is described in section 2 and the simulation model with its input parameters in section 3. The comparison of the simulation model with the experimental data and the effect of water admixtures on the evolution of the helium DBD are presented in section 4. Conclusions are presented in section 5.

\section{Experimental setup}

In order to ensure the correctness of the numerical model, experimental data are compared with simulation results. The experimental setup is shown in Figure 1. It consists of two parallel plate copper electrodes $(10.4 \mathrm{~cm} \times 5.0 \mathrm{~cm})$ deposited on a dielectric layer of a glass $\left(\varepsilon_{\mathrm{r}}=8\right)$ with thickness of $1.2 \mathrm{~mm}$ each. The distance between the dielectrics is kept constant at $5.0 \mathrm{~mm}$. A high-voltage amplifier (Trek, Inc., model PD07016) driven by an arbitrary waveform generator 
(Tektronix, model AFG3022C) is used to operate the discharge. This feeds the upper electrode, through a current limiting resistor (5 kOhms), with a sinusoidal voltage of $2.5 \mathrm{kV}$ amplitude peak to peak and frequency of $10 \mathrm{kHz}$. The other electrode is grounded. The electrodedielectrics assembly, forming the discharge gap is placed in the centre of a stainless steel chamber, connected to the vacuum system and the helium flowmeter output [41]. Before conducting the experiments, the stainless steel chamber is heated and pumped down to $10^{-5}$ torr. The flow of helium (4.6 spectral purity, Linde) is controlled using a mass flow controller (MKS 1179A coupled) and is kept constant at $2.2 \mathrm{l} / \mathrm{min}(0.7 \mathrm{~s}$ residence time inside the gap). The pressure is kept slightly higher than ambient, at 780 torr to reduce the possibility of air intake into the chamber due to leakage.

The applied voltage, measured close to the HV electrode using a high-voltage probe (Tektronix P6015A), and the current measured on the ground line by a current monitor (Pearson 6585), are displayed and stored using a digital oscilloscope (Tektronix TDS 5034B, $350 \mathrm{MHz}$ Bandwidth and $5 \mathrm{GS} / \mathrm{s}$ Sample Rate). The average of 50 consecutive acquisitions is considered here. The gas temperature is estimated using the rotational distribution in the emission spectrum of the first negative system of $\mathrm{N}_{2}{ }^{+}\left(\left(\mathrm{B}^{2} \sum_{\mathrm{u}}{ }^{+}, \mathrm{v}_{\mathrm{B}}=0\right) \rightarrow\left(\mathrm{X}^{2} \sum_{\mathrm{g}}{ }^{+}, \mathrm{v}_{\mathrm{X}}=0\right)\right)$, by the Boltzmann plot method, under the assumption that the rotational temperature reflects that of the gas molecules inside the plasma $[42,43]$. Using this method, the gas temperature is estimated to be around 300 $\mathrm{K}$. The experimental setup is shown in Figure 1 and operational parameters are summarized in Table 1 .

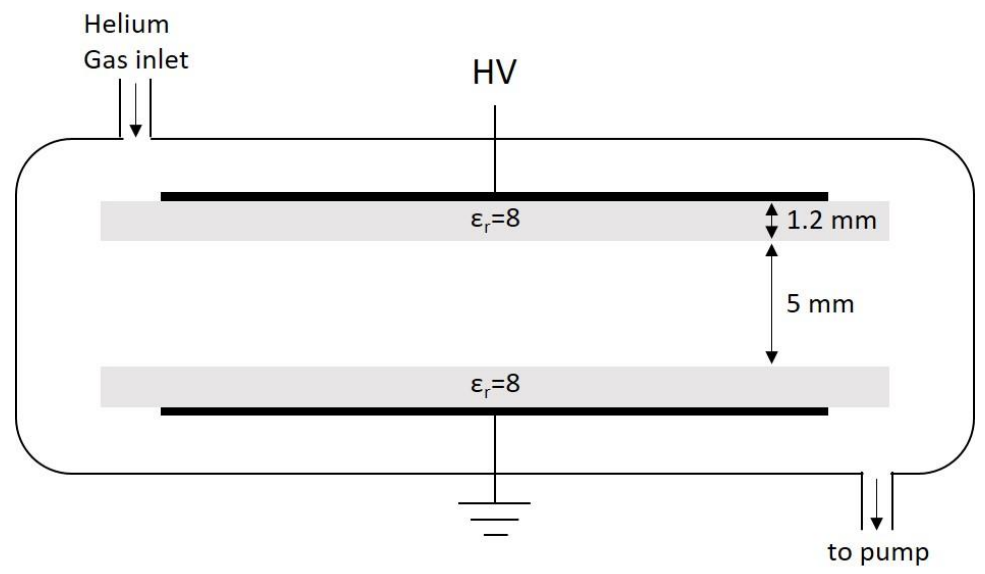

Figure 1: Detail of experimental DBD configuration, not to scale.

Table 1: Operational parameters of the experimental setup.

\begin{tabular}{lc}
\hline \hline Relative permittivity $\left(\varepsilon_{\mathrm{r}}\right)$ & 8 \\
Gap between dielectrics $(\mathrm{mm})$ & 5.0 \\
Dielectric thickness $(\mathrm{mm})$ & 1.2 \\
Electrode area $\left(\mathrm{cm}^{2}\right)$ & 52 \\
Gas pressure $($ torr $)$ & 780 \\
Gas temperature $(\mathrm{K})$ & 300 \\
Voltage $_{\mathrm{p}-\mathrm{p}}(\mathrm{kV})$ & 2.5 \\
Voltage waveform $_{\text {Frequency }(\mathrm{kHz})}$ & sinusoidal \\
Helium gas purity $(\%)$ & 10 \\
Total gas flow rate $(1 / \mathrm{min})$ & 99.996 \\
\hline \hline
\end{tabular}

\section{Simulation model and input parameters}

In this study the plasma fluid model (PFM) $[44,45]$ is used for the description of a helium DBD in the presence of nitrogen, oxygen and water species. The model equations and boundary conditions are presented in detail in previous work [46] and for this reason they will only be 
briefly mentioned here. For electron and electron energy the continuity equation in the drift diffusion approximation is used as follows:

$$
\begin{gathered}
\frac{\partial n_{e}}{\partial t}+\nabla \cdot \vec{\Gamma}_{e}=S_{e} \\
\frac{\partial n_{\varepsilon}}{\partial t}+\nabla \cdot \vec{\Gamma}_{\varepsilon}=-e \vec{\Gamma}_{e} \cdot \vec{E}+S_{\varepsilon}
\end{gathered}
$$

where $n_{e}$ and $n_{\varepsilon}$ is the electron and electron energy density respectively, $\vec{\Gamma}_{e}$ and $\vec{\Gamma}_{\varepsilon}$ is the flux of electron and electron energy respectively, $S_{e}$ is the source term for the production-destruction of electrons, $S_{\varepsilon}$ is the source term that accounts for the energy gain or loss in elastic and inelastic collisions of electrons with the heavy species in the mixture, $\vec{E}$ is the electric field and $\vec{\Gamma}_{e} \cdot \vec{E}$ accounts for the contribution of Joule heat. For the heavy species (neutral, excited and ion species) the multi-component diffusion equation is used.

$$
\rho \frac{\partial}{\partial t}\left(\omega_{i}\right)+\rho(u \cdot \nabla) \omega_{i}=\nabla \cdot \vec{J}_{i}+S_{i}, \quad i=1, \ldots, Q-1
$$

where $\rho$ is the density of the mixture, $\omega_{i}$ the mass fraction of species $i, \vec{J}_{i}$ the diffusive flux vector, $S_{i}$ the source term and $Q$ is the number of heavy species in the mixture. The density of the background gas (helium) is calculated from the equation $\omega=1-\sum_{i=1}^{Q-1} \omega_{i}$. The above equations (1-3) are coupled with Poisson's equation for the description of the electric field. The boundary condition considered for the electrons is that when they reach the dielectric they are adsorbed. On the other hand, secondary electrons are emitted from the dielectric surface, due to the bombardment of the dielectric surface by heavy species. For the heavy species in the mixture, it is considered that when heavy species reach the dielectric surface (due to their random motion and the motion from the electric field) they are converted to their ground state as shown in Table 4. The model considers also the charge deposited on the dielectric surfaces. The plasma chemistry of the model considers 56 species and 496 reaction channels. The species considered in the model and the reactions channels are presented in Table 2 and Table A1 (in Appendix A) respectively. The rate coefficients of the reactions 1-3, 25-38, 63-78, 159-169 and the transport properties of the electrons and electron energy are calculated from the solution of the Boltzmann equation in the two term approximation [44]. This procedure is described in detail in previous work [46]. The mobilities of the species $\mathrm{He}^{+}, \mathrm{He}_{2}^{+}, \mathrm{N}_{2}{ }^{+}, \mathrm{N}_{4}^{+}, \mathrm{O}_{2}{ }^{+}, \mathrm{O}_{4}{ }^{+}, \mathrm{O}^{-}$, $\mathrm{O}_{2}^{-}, \mathrm{O}_{3}^{-}, \mathrm{H}_{2} \mathrm{O}^{+}, \mathrm{H}_{3} \mathrm{O}^{+}, \mathrm{H}_{5} \mathrm{O}_{2}{ }^{+}, \mathrm{H}_{7} \mathrm{O}_{3}{ }^{+}, \mathrm{H}_{9} \mathrm{O}_{4}{ }^{+}, \mathrm{H}_{11} \mathrm{O}_{5}{ }^{+}, \mathrm{H}_{13} \mathrm{O}_{6}{ }^{+}, \mathrm{H}_{15} \mathrm{O}_{7}{ }^{+}, \mathrm{H}_{17} \mathrm{O}_{8}{ }^{+}, \mathrm{H}_{19} \mathrm{O}_{9}{ }^{+}, \mathrm{H}^{-}, \mathrm{OH}^{-}$, $\mathrm{H}_{3} \mathrm{O}_{2}^{-}, \mathrm{H}_{5} \mathrm{O}_{3}^{-}, \mathrm{H}^{+}, \mathrm{H}_{2}^{+}, \mathrm{OH}^{+}, \mathrm{H}_{4} \mathrm{O}_{2}^{+}, \mathrm{H}_{2} \mathrm{O}_{3}^{+}, \mathrm{HeH}^{+}$are taken from [28,47]. The diffusion coefficients for the species $\mathrm{He}, \mathrm{O}_{2}, \mathrm{O}_{3}, \mathrm{H}_{2} \mathrm{O}, \mathrm{H}_{2}, \mathrm{HO}_{2}, \mathrm{H}, \mathrm{H}_{2} \mathrm{O}_{2}$ and $\mathrm{H}_{2} \mathrm{O}_{2}{ }^{-}$are calculated from the kinetic theory [48,49] and the diffusion coefficient for the $\mathrm{He}_{\mathrm{m}}, \mathrm{He}_{2}{ }^{*}, \mathrm{~N}, \mathrm{~N}_{2}, \mathrm{~N}_{2}(\mathrm{v}), \mathrm{N}_{2}(\mathrm{~A})$, $\mathrm{N}_{2}(\mathrm{~B}), \mathrm{N}_{2}(\mathrm{a}), \mathrm{N}_{2}(\mathrm{C}), \mathrm{O}, \mathrm{O}\left({ }^{1} \mathrm{~S}\right), \mathrm{O}\left({ }^{1} \mathrm{D}\right), \mathrm{O}_{2}(\mathrm{v}), \mathrm{O}_{2}(\mathrm{a}), \mathrm{O}_{2}(\mathrm{~b}), \mathrm{OH}$ and $\mathrm{OH}(\mathrm{A})$ are taken from literature $[50,28]$.

The air impurities considered in the model (for comparison purposes with the experiment of section 2) are presented in Table 3, unless otherwise stated. These are due to the air remaining in the discharge chamber after its heating and pumping down to $10^{-5}$ Torr, and air impurities from the helium bottle. The low level of relative humidity (10\%) considered in the air remaining in the discharge chamber, is due to the heating of the discharge chamber. The levels of $\mathrm{N}_{2}, \mathrm{O}_{2}$ and $\mathrm{H}_{2} \mathrm{O}$ impurities from the helium bottle were lower than the maximum values given by the producer because a brand-new full helium bottle was used and the heavier $\mathrm{N}_{2}, \mathrm{O}_{2}$ and $\mathrm{H}_{2} \mathrm{O}$ species have a lower probability of being exported from the bottle compared to He. In summary, the heating and pumping of the chamber, the continuous flow and the higher pressure of helium than atmosphere in the chamber ensures a high helium purity in the discharge chamber. The numerical model confirmed this, as a low level of air impurities (as seen in Table 3) was required for matching with the experimental results.

The surface reactions, reaction probabilities, secondary electron emission coefficient (SEEC) and mean energy of secondary electrons (MESE) considered on the dielectric surfaces are given in Table 4. The surface reactions and reaction probabilities are taken from 
$[51,38,52,28,40]$. The SEEC is set to 0.015 because it gives the best agreement with the experimental results. It is noted that such coefficients in simulation models are adjusted $[53,54]$ to match the experimental results.

For all the species in the mixture, a uniform initial density of $10^{13} \mathrm{~m}^{-3}$ was set (except for the He which is the background gas, and the densities of $\mathrm{N}_{2}, \mathrm{O}_{2}$ and $\mathrm{H}_{2} \mathrm{O}$ which are defined based on the level of air content in the mixture (see Table 3). It is noted that different initial densities have also been used in the range of $10^{11}-10^{14} \mathrm{~m}^{-3}$ yielding similar simulation results.

The equations of the plasma fluid model are solved using the plasma module of the COMSOL multiphysics simulation package [55] on an Intel Xenon E5-2667 V4 $3.2 \mathrm{kHz}$ (with 16 core) server. These equations are discretized by the Galerkin finite element method using linear element shape functions. The resulting system is solved using the direct solver PARDISO [56]. For the time integration, the backward Euler method is used. The model considers 554 elements and 26556 degrees of freedom, with the smaller mesh size of $10 \mu \mathrm{m}$ located in the region of the plasma and the larger mesh size of $50 \mu \mathrm{m}$ located in the dielectrics. Each simulation was run for 12 voltage cycles and it required about two (2) days to be performed.

Table 2: Species included in the model chemistry.

\begin{tabular}{|c|c|c|}
\hline \\
\hline \multicolumn{2}{|l|}{ Electrons } & $\mathrm{e}^{-}$ \\
\hline & Ions & $\mathrm{He}^{+}, \mathrm{He}_{2}^{+}$ \\
\hline Hellum & Neutrals & $\mathrm{He}, \mathrm{He}_{\mathrm{m}}, \mathrm{He}_{2} *$ \\
\hline & Ions & $\mathrm{N}_{2}^{+}, \mathrm{N}_{4}^{+}$ \\
\hline Nitrogen & Neutrals & $\mathrm{N}, \mathrm{N}_{2}, \mathrm{~N}_{2}(\mathrm{v}), \mathrm{N}_{2}(\mathrm{~A}), \mathrm{N}_{2}(\mathrm{~B}), \mathrm{N}_{2}(\mathrm{a}), \mathrm{N}_{2}(\mathrm{C})$ \\
\hline Oxyoen & Ions & $\mathrm{O}_{2}^{+}, \mathrm{O}_{4}^{+}, \mathrm{O}^{-}, \mathrm{O}_{2}^{-}, \mathrm{O}_{3}^{-}$ \\
\hline Uxygen & Neutrals & $\mathrm{O}, \mathrm{O}_{2}, \mathrm{O}_{3}, \mathrm{O}\left({ }^{1} \mathrm{~S}\right), \mathrm{O}\left({ }^{1} \mathrm{D}\right), \mathrm{O}_{2}(\mathrm{v}), \mathrm{O}_{2}(\mathrm{a}), \mathrm{O}_{2}(\mathrm{~b})$ \\
\hline Water & Ions & $\begin{array}{l}\mathrm{H}_{2} \mathrm{O}^{+}, \mathrm{H}_{2} \mathrm{O}_{3}{ }^{+}, \mathrm{H}_{3} \mathrm{O}^{+}, \mathrm{H}_{4} \mathrm{O}_{2}^{+}, \mathrm{H}_{5} \mathrm{O}_{2}^{+}, \mathrm{H}_{7} \mathrm{O}_{3}^{+}, \mathrm{H}_{9} \mathrm{O}_{4}{ }^{+}, \\
\mathrm{H}_{11} \mathrm{O}_{5}^{+}, \mathrm{H}_{13} \mathrm{O}_{6}^{+}, \mathrm{H}_{15} \mathrm{O}_{7}^{+}, \mathrm{H}_{17} \mathrm{O}_{8}^{+}, \mathrm{H}_{19} \mathrm{O}_{9}^{+}, \mathrm{H}_{3} \mathrm{O}_{2}^{-}, \\
\mathrm{H}_{5} \mathrm{O}_{3}^{-}\end{array}$ \\
\hline & Neutrals & $\mathrm{H}_{2} \mathrm{O}$ \\
\hline Others & Ions & $\mathrm{H}^{+}, \mathrm{H}_{2}^{+}, \mathrm{OH}^{+}, \mathrm{HeH}^{+}, \mathrm{H}^{-}, \mathrm{OH}^{-}, \mathrm{H}_{2} \mathrm{O}_{2}^{-}$ \\
\hline & Neutrals & $\mathrm{H}, \mathrm{H}_{2}, \mathrm{OH}, \mathrm{OH}(\mathrm{A}), \mathrm{HO}_{2}, \mathrm{H}_{2} \mathrm{O}_{2}$ \\
\hline
\end{tabular}

$\mathrm{He}_{\mathrm{m}}$ represents $\mathrm{He}\left(2^{3} \mathrm{~S}\right)$ and $\mathrm{He}\left(2^{1} \mathrm{~S}\right) ; \mathrm{He}_{2}^{*}$ represents $\mathrm{He}_{2}\left(\mathrm{a}^{3} \Sigma_{\mathrm{u}}^{+}\right) ; \mathrm{N}_{2}(\mathrm{v})$ represents the vibrational excited states of $\mathrm{N}_{2}(\mathrm{v}=1-10) ; \mathrm{N}_{2}(\mathrm{~A})$ represents $\mathrm{N}_{2}\left(\mathrm{~A}^{3} \Sigma_{\mathrm{u}}^{+}(\mathrm{v}=0-4)\right)$, $\mathrm{N}_{2}\left(\mathrm{~A}^{3} \Sigma_{\mathrm{u}}^{+}(\mathrm{v}=5-9)\right)$ and $\mathrm{N}_{2}\left(\mathrm{~A}^{3} \Sigma_{\mathrm{u}}^{+}(\mathrm{v}>9)\right) ; \mathrm{N}_{2}(\mathrm{~B})$ represents $\mathrm{N}_{2}\left(\mathrm{~B}^{3} \Pi_{\mathrm{g}}\right), \mathrm{N}_{2}\left(\mathrm{~W}^{3} \Delta_{\mathrm{u}}\right)$ and $\mathrm{N}_{2}\left(\mathrm{~B}^{3} \Sigma_{\mathrm{u}}^{-}\right) ; \mathrm{N}_{2}(\mathrm{a})$ represents $\mathrm{N}_{2}\left(\mathrm{a}^{1} \Sigma_{\mathrm{u}}^{-}\right), \mathrm{N}_{2}\left(\mathrm{a}^{1} \Pi_{\mathrm{g}}\right)$ and $\mathrm{N}_{2}\left(\mathrm{~W}^{1} \Delta_{\mathrm{u}}\right) ; \mathrm{N}_{2}(\mathrm{C})$ represents $\mathrm{N}_{2}\left(\mathrm{C}^{3} \Pi_{\mathrm{u}}\right), \mathrm{N}_{2}\left(\mathrm{E}^{3} \Sigma_{\mathrm{g}}^{+}\right)$and $\mathrm{N}_{2}\left(\mathrm{a}^{1} \Sigma_{\mathrm{g}}^{+}\right) ; \quad \mathrm{O}_{2}(\mathrm{a})$ represents $\mathrm{O}_{2}\left(\mathrm{a}^{1} \Delta_{\mathrm{g}}\right) ; \mathrm{O}_{2}$ (b) represents $\mathrm{O}_{2}\left(\mathrm{~b}^{1} \Sigma_{\mathrm{g}}^{+}\right) ; \mathrm{O}_{2}(\mathrm{v})$ represents the vibrational excited states of $\mathrm{O}_{2}(\mathrm{v}=1-4)$.

Table 3: Air impurities considered for the comparison of the simulation model with the experiment results of section 2 .

\begin{tabular}{|c|c|c|c|}
\hline Species & $\begin{array}{c}\text { Discharge Chamber } \\
(\mathrm{ppm})^{\mathrm{a}}\end{array}$ & $\begin{array}{l}\text { Helium Bottle } \\
(\mathrm{ppm})^{\mathrm{b}}\end{array}$ & $\begin{array}{r}\text { Total } \\
(\mathrm{ppm})\end{array}$ \\
\hline $\mathrm{N}_{2}$ & 15.8 (79\% of air) & 10 & 25.8 \\
\hline $\mathrm{O}_{2}$ & 4.2 (21\% of air) & 1 & 5.2 \\
\hline $\mathrm{H}_{2} \mathrm{O}$ & $\begin{array}{c}0.05 \text { (10\% relative } \\
\text { humidity) }\end{array}$ & 1.5 & 1.55 \\
\hline
\end{tabular}

\footnotetext{
a) Air impurities (20 ppm) remaining in the chamber after heating and pumping down to $10^{-5}$ Torr.

b) Air impurities in the helium bottle. The suppliers quote maximum impurity levels in the 99.996\% grade helium as being $\mathrm{N}_{2} 20 \mathrm{ppm}, \mathrm{O}_{2} 5 \mathrm{ppm}$ and $\mathrm{H}_{2} \mathrm{O} 5 \mathrm{ppm}$.
}

Table 4: Surface reactions, reaction probabilities, SEEC and MESE. 


\begin{tabular}{|c|c|c|c|c|}
\hline No & Surface Reaction $^{\text {a) }}$ & Reaction probability $^{\text {a) }}$ & SEEC & MESE \\
\hline 1 & $\mathrm{He}_{\mathrm{m}}+$ Surface $\rightarrow \mathrm{He}$ & 1 & $1.5 \mathrm{e}-2$ & 5 \\
\hline 2 & $\mathrm{He}_{2}^{*}+$ Surface $\rightarrow 2 \mathrm{He}$ & 1 & $1.5 \mathrm{e}-2$ & 5 \\
\hline 3 & $\mathrm{He}^{+}+$Surface $\rightarrow \mathrm{He}$ & 1 & $1.5 \mathrm{e}-2$ & 5 \\
\hline 4 & $\mathrm{He}_{2}^{+}+$Surface $\rightarrow 2 \mathrm{He}$ & 1 & $1.5 \mathrm{e}-2$ & 5 \\
\hline 5 & $\mathrm{~N}+$ Surface $\rightarrow 0.5 \mathrm{~N}_{2}$ & 0.01 & 0 & 0 \\
\hline 6 & $\mathrm{~N}_{2}(A)+$ Surface $\rightarrow \mathrm{N}_{2}$ & 0.5 & $1.5 \mathrm{e}-2$ & 1 \\
\hline 7 & $\mathrm{~N}_{2}(B)+$ Surface $\rightarrow \mathrm{N}_{2}$ & 0.5 & $1.5 \mathrm{e}-2$ & 1 \\
\hline 8 & $\mathrm{~N}_{2}(a)+$ Surface $\rightarrow \mathrm{N}_{2}$ & 0.5 & $1.5 \mathrm{e}-2$ & 1 \\
\hline 9 & $\mathrm{~N}_{2}(C)+$ Surface $\rightarrow \mathrm{N}_{2}$ & 0.5 & $1.5 \mathrm{e}-2$ & 1 \\
\hline 10 & $\mathrm{~N}_{2}^{+}+$Surface $\rightarrow \mathrm{N}_{2}$ & 1 & $1.5 \mathrm{e}-2$ & 3 \\
\hline 11 & $\mathrm{~N}_{4}^{+}+$Surface $\rightarrow 2 \mathrm{~N}_{2}$ & 1 & $1.5 \mathrm{e}-2$ & 3 \\
\hline 12 & $0+$ Surface $\rightarrow 0.5 \mathrm{O}_{2}$ & 0.02 & 0 & 0 \\
\hline 13 & $\mathrm{O}\left({ }^{1} D\right)+$ Surface $\rightarrow 0$ & 1 & 0 & 0 \\
\hline 14 & $\mathrm{O}\left({ }^{1} S\right)+$ Surface $\rightarrow 0$ & 1 & 0 & 0 \\
\hline 15 & $\mathrm{O}_{2}(v)+$ Surface $\rightarrow \mathrm{O}_{2}$ & 0.2 & 0 & 0 \\
\hline 16 & $\mathrm{O}_{2}(a)+$ Surface $\rightarrow \mathrm{O}_{2}$ & 0.0004 & 0 & 0 \\
\hline 17 & $\mathrm{O}_{2}(b)+$ Surface $\rightarrow \mathrm{O}_{2}$ & 0.02 & 0 & 0 \\
\hline 18 & $\mathrm{O}_{3}+$ Surface $\rightarrow \mathrm{O}_{3}$ & 1 & 0 & 0 \\
\hline 19 & $\mathrm{O}^{-}+$Surface $\rightarrow 0.5 \mathrm{O}_{2}$ & 1 & 0 & 0 \\
\hline 20 & $\mathrm{O}_{2}^{-}+$Surface $\rightarrow \mathrm{O}_{2}$ & 1 & 0 & 0 \\
\hline 21 & $\mathrm{O}_{3}^{-}+$Surface $\rightarrow \mathrm{O}_{3}$ & 1 & 0 & 0 \\
\hline 22 & $\mathrm{O}_{2}^{+}+$Surface $\rightarrow \mathrm{O}_{2}$ & 1 & $1.5 \mathrm{e}-2$ & 3 \\
\hline 23 & $\mathrm{O}_{4}^{+}+$Surface $\rightarrow 2 \mathrm{O}_{2}$ & 1 & $1.5 \mathrm{e}-2$ & 3 \\
\hline 24 & $\mathrm{H}+$ Surface $\rightarrow 0.5 \mathrm{H}_{2}$ & 0.03 & 0 & 0 \\
\hline 25 & $\mathrm{H}^{+}+$Surface $\rightarrow \mathrm{H}$ & 1 & $1.5 \mathrm{e}-2$ & 3 \\
\hline 26 & $\mathrm{H}^{-}+$Surface $\rightarrow \mathrm{H}$ & 1 & 0 & 0 \\
\hline 27 & $\mathrm{H}_{2}^{+}+$Surface $\rightarrow \mathrm{H}_{2}$ & 1 & $1.5 \mathrm{e}-2$ & 3 \\
\hline 28 & $\mathrm{OH}(a)+$ Surface $\rightarrow \mathrm{OH}$ & 1 & 0 & 0 \\
\hline 29 & $\mathrm{OH}+$ Surface $\rightarrow 0.5 \mathrm{H}_{2} \mathrm{O}_{2}$ & 0.03 & 0 & 0 \\
\hline 30 & $\mathrm{OH}^{+}+$Surface $\rightarrow \mathrm{OH}$ & 1 & $1.5 \mathrm{e}-2$ & 3 \\
\hline 31 & $\mathrm{OH}^{-}+$Surface $\rightarrow \mathrm{OH}$ & 1 & 0 & 0 \\
\hline 32 & $\mathrm{HeH}^{+}+$Surface $\rightarrow \mathrm{He}+\mathrm{H}$ & 1 & $1.5 \mathrm{e}-2$ & 3 \\
\hline 33 & $\mathrm{H}_{2} \mathrm{O}^{+}+$Surface $\rightarrow \mathrm{H}_{2} \mathrm{O}$ & 1 & $1.5 \mathrm{e}-2$ & 3 \\
\hline 34 & $\mathrm{H}_{2} \mathrm{O}_{3}^{+}+$Surface $\rightarrow \mathrm{H}_{2} \mathrm{O}+\mathrm{O}_{2}$ & 1 & $1.5 \mathrm{e}-2$ & 3 \\
\hline 35 & $\mathrm{H}_{3} \mathrm{O}^{+}+$Surface $\rightarrow \mathrm{H}+\mathrm{H}_{2} \mathrm{O}$ & 1 & $1.5 \mathrm{e}-2$ & 3 \\
\hline 36 & $\mathrm{H}_{4} \mathrm{O}_{2}^{+}+$Surface $\rightarrow 2 \mathrm{H}_{2} \mathrm{O}$ & 1 & $1.5 \mathrm{e}-2$ & 3 \\
\hline 37 & $\mathrm{H}_{5} \mathrm{O}_{2}^{+}+$Surface $\rightarrow \mathrm{H}+2 \mathrm{H}_{2} \mathrm{O}$ & 1 & $1.5 \mathrm{e}-2$ & 3 \\
\hline 38 & $\mathrm{H}_{7} \mathrm{O}_{3}^{+}+$Surface $\rightarrow \mathrm{H}+3 \mathrm{H}_{2} \mathrm{O}$ & 1 & $1.5 \mathrm{e}-2$ & 3 \\
\hline 39 & $\mathrm{H}_{9} \mathrm{O}_{4}^{+}+$Surface $\rightarrow \mathrm{H}+4 \mathrm{H}_{2} \mathrm{O}$ & 1 & $1.5 \mathrm{e}-2$ & 3 \\
\hline 40 & $\mathrm{H}_{11} \mathrm{O}_{5}^{+}+$Surface $\rightarrow \mathrm{H}+5 \mathrm{H}_{2} \mathrm{O}$ & 1 & $1.5 \mathrm{e}-2$ & 3 \\
\hline 41 & $\mathrm{H}_{13} \mathrm{O}_{6}^{+}+$Surface $\rightarrow \mathrm{H}+6 \mathrm{H}_{2} \mathrm{O}$ & 1 & $1.5 \mathrm{e}-2$ & 3 \\
\hline 42 & $\mathrm{H}_{2} \mathrm{O}_{2}^{-}+$Surface $\rightarrow \mathrm{H}_{2} \mathrm{O}_{2}$ & 1 & 0 & 0 \\
\hline 43 & $\mathrm{H}_{3} \mathrm{O}_{2}^{-}+$Surface $\rightarrow \mathrm{OH}+\mathrm{H}_{2} \mathrm{O}$ & 1 & 0 & 0 \\
\hline 44 & $\mathrm{H}_{5} \mathrm{O}_{3}^{-}+$Surface $\rightarrow \mathrm{OH}+2 \mathrm{H}_{2} \mathrm{O}$ & 1 & 0 & 0 \\
\hline
\end{tabular}

${ }^{\mathrm{a}} \operatorname{ref}[51,38,52,28,40]$

\section{Results and discussion}

\subsection{Comparison of the simulation model with the experimental results}

In order to ensure the validity of the numerical model, the simulation results are compared with experimental measurements. The comparison is based on the electrical characteristics as taken from the experiment and the numerical model. Figure 2 presents the discharge current and the applied voltage as measured from the experimental configuration presented in section 
2 and the simulation model with level of air impurities (31 ppm) as determined in Table 3 . The experimental results were obtained for DBD working in continuous He flow at 780 Torr. From Figure 2, it can be observed that the measured voltage presents a collapse during the discharge current. Similar collapse is also observed in other experimental studies [57]. For the simulation, the applied voltage presented in the figure is the input sinusoidal voltage on the upper electrode.

As it can be observed, there is good agreement between the experimental discharge current and simulation results, with an error on the peak value less than $10 \%$. The experimental discharge current consists of a single narrow current pulse, of relatively large peak value (about $60 \mathrm{~mA}$ ) per half-cycle of the external voltage fact which is attributed to the homogenous mode of DBD, thus the discharge can be treated as one-dimensional. Furthermore, in both cases the discharge current occurs at the same time during the rising and falling part of the applied voltage. The above analysis gives us confidence on the ability of the model to capture the physics behind these kind of discharges and can be used to study the effect of water admixtures on the evolution of He/air discharges.

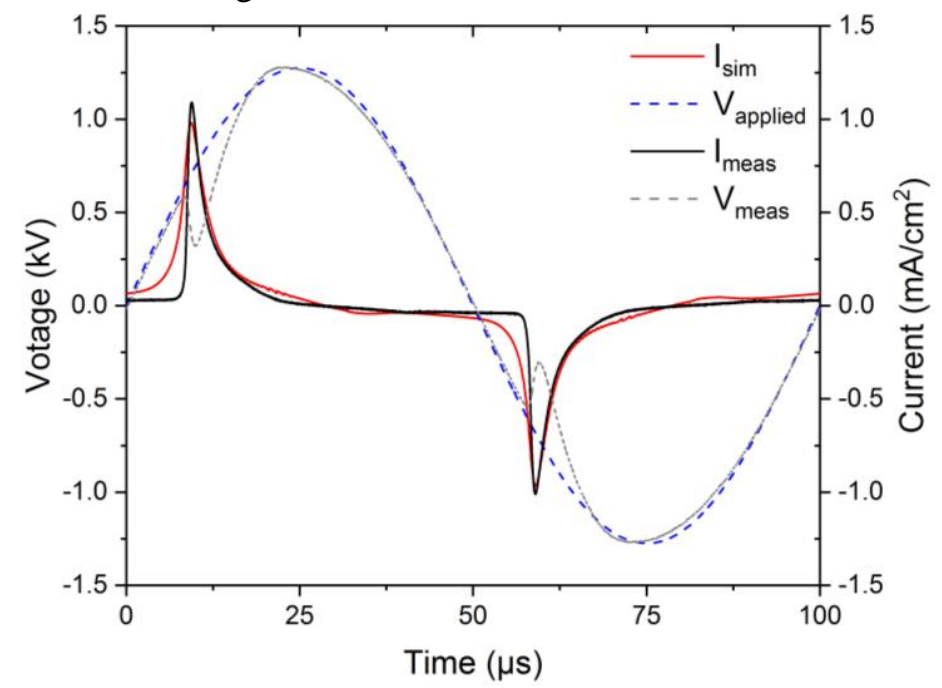

Figure 2: Comparison between simulation and measured discharge characteristics (current and voltage).

In order to investigate the discharge development, the spatio-temporal evolution of the total ionization rate in logarithmic scale is presented in Figure 3. The polarity of the applied voltage is illustrated in the graph. As it can be seen, during the rising part of the applied voltage, the ionization wave begins from the anode and propagates towards the cathode, which is characteristic of a glow discharge. The maximum of the ionization rate occurs at the peak of the discharge current and close to the cathode. After the breakdown, charges accumulate on the dielectric surface, creating an electric field in the opposite direction to that of the applied voltage. The reduced voltage in the gap causes the ionization rate to reduce as well after breakdown. During the falling part of the applied voltage, the voltage polarity in the gap changes (as can be seen from Figure 3), and the ionization wave propagates in the opposite direction. The maximum of the ionization rate occurs at the peak of the discharge current and close to the cathode, indicating that the discharge exhibits glow characteristics. 


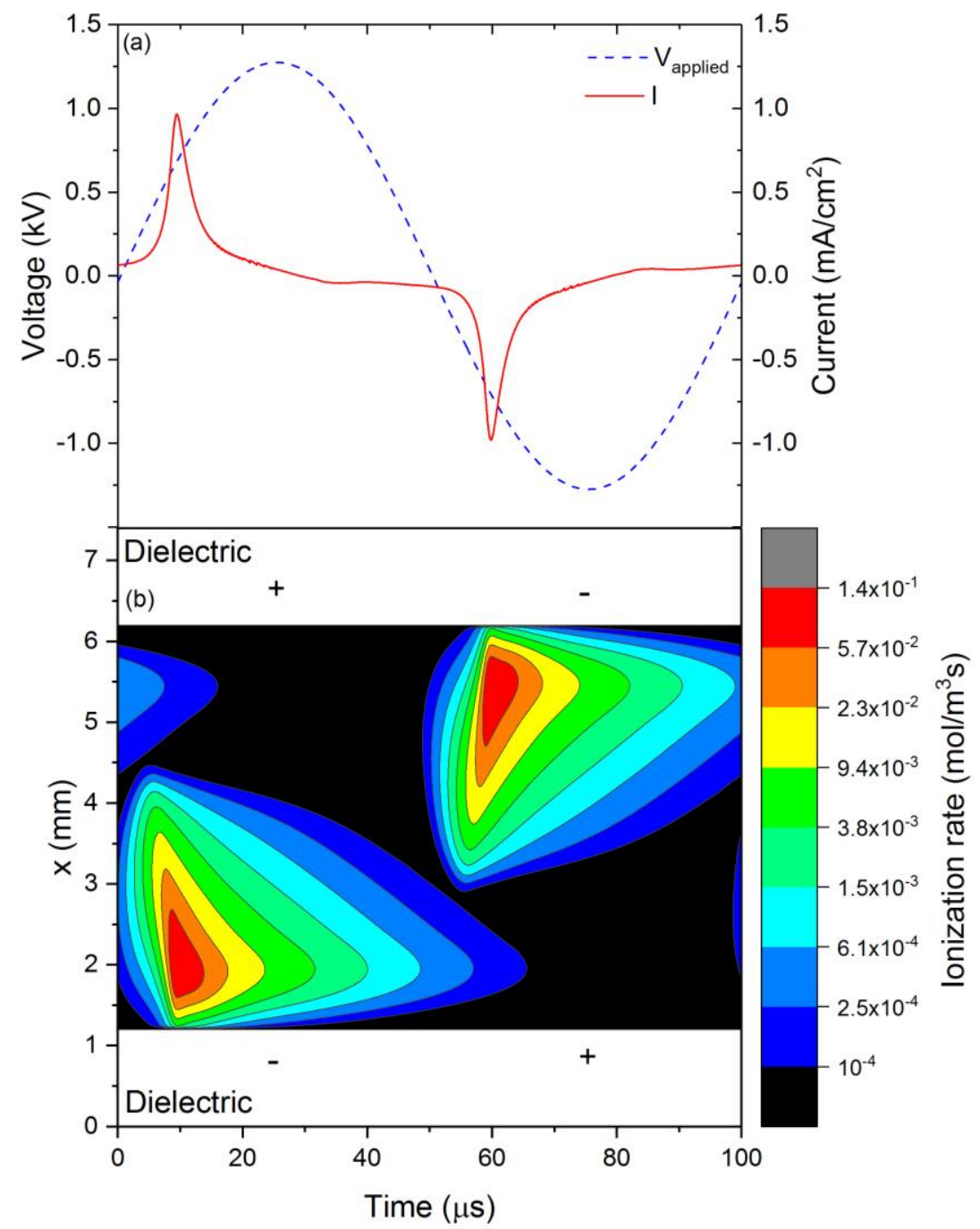

Figure 3: Simulation results of (a) the applied voltage and discharge current, and (b) the spatiotemporal evolution of the total ionization rate in logarithmic scale over a voltage cycle.

\subsection{Effect of water admixtures on the discharge characteristics of a Heldry air (500 ppm) $D B D$}

In this section, the level of water admixtures is varied in the range of 20-2000 ppm and its effect on the discharge characteristics of a helium/dry air discharge is investigated. The level of dry air in the helium DBD is considered to be $500 \mathrm{ppm}\left(79 \% \mathrm{~N}_{2}\right.$ and $\left.21 \% \mathrm{O}_{2}\right)$, as this is a plausible value for atmospheric pressure discharges without any vacuum equipment [37]. In the range of water admixtures considered in this study, the discharge exhibits symmetric characteristics. Figure 4 presents the discharge characteristics (applied voltage, gap voltage and discharge current) for two different levels of water admixtures (50 and $500 \mathrm{ppm}$ ). As can be seen, in both cases the discharge characteristics are symmetric, with one current pulse per half voltage cycle, at the same absolute amplitude and shape. After the breakdown, the gap voltage reduces significantly due to the charge accumulation on the dielectric surfaces shielding the electric field of the applied voltage [46]. As the applied voltage increases and just prior to its maximum, there is a second peak of the gap voltage. However, that gap voltage is not sufficient to ignite a second discharge.

Comparing the discharge characteristics for these two cases of water admixtures (50 and $500 \mathrm{ppm}$ ), two differences can be observed regarding the discharge current and the gap voltage. The amplitude of the discharge current is higher for the case of $500 \mathrm{ppm}$ water admixture, however, its current pulse width is narrower. On the other hand, the breakdown voltage is lower 
for the case of $500 \mathrm{ppm}$, while, its secondary gap voltage peak is higher. Similar observations have be made in literature [58].
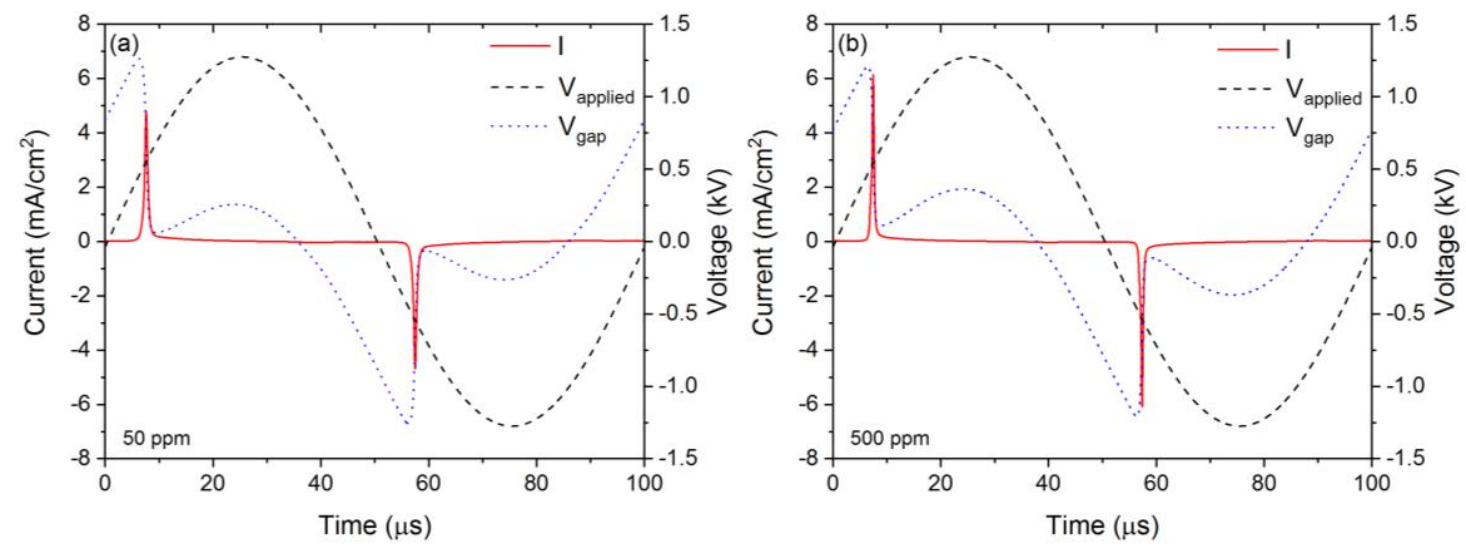

Figure 4: Simulation results of the discharge characteristics (applied voltage, gap voltage and discharge current) for (a) $50 \mathrm{ppm}$ and (b) $500 \mathrm{ppm}$ of water admixtures in a He/dry air (500 ppm) DBD.

In order to further investigate the effect of water admixtures on the discharge characterisitcs, the breakdown voltage, the amplitude of the discharge current and the second peak of the gap voltage at different levels of water admixtures are presented in Figure 5. As it can be seen, the breakdown voltage reduces as the level of water increases in the mixture (up to $\sim 600 \mathrm{ppm}$ ). This is due to the enhancement of water-related reactions (such as the Penning ionization reaction, charge transfer reaction, etc.). From the schematic diagram of Figure 8 it can be seen that the ion production is initiated by the increase of $\mathrm{He}_{\mathrm{m}}$ and $\mathrm{He}^{+}$(this is consistent with our previous work [46]). Although the energy threshold for the production of $\mathrm{He}_{\mathrm{m}}$ and $\mathrm{He}^{+}$ is higher in comparison to the direct ionization of $\mathrm{N}_{2}, \mathrm{O}_{2}$ and $\mathrm{H}_{2} \mathrm{O}$, direct ionization is not important for low levels of impurities, as can be seen in Figure 10. For low levels of impurities, the ionization of these species is mainly due to Penning ionization with $\mathrm{He}_{\mathrm{m}}$. The discharge is ignited when the $\mathrm{He}_{\mathrm{m}}$ and $\mathrm{He}^{+}$reach the necessary values for the production of adequate ions which are able to trigger breakdown. By increasing the concentration of water in the mixture, the reactions associated with water, (i.e. reactions ..., 221, 222, 223, .. 286, 287, 288, ...) also benefit, and as a result a lower concentration of $\mathrm{He}_{\mathrm{m}}$ and $\mathrm{He}^{+}$is required for ion production. Since the concentration of $\mathrm{He}_{\mathrm{m}}$ and $\mathrm{He}^{+}$depends on the gap voltage, the reduction in $\mathrm{He}_{\mathrm{m}}$ and $\mathrm{He}^{+}$will result in a lower breakdown voltage. As the water impurities increase (higher than 600 $\mathrm{ppm})$ the attachment of electrons becomes important, and the breakdown voltage starts increasing.

From Figure 5 it can be observed that the amplitude of the discharge current has a sharp increase for up to $600 \mathrm{ppm}$ of water and at higher levels it starts approaching a constant value. The sharp increase of the discharge current peak is caused by the benefit of $\mathrm{H}_{2} \mathrm{O}$-related reactions that increases the ionization rate and consequently the amplitude of the discharge current. However, above $600 \mathrm{ppm}$ of water, the attachment of electrons becomes important. The two effects balance each other out resulting in a somewhat constant current above $600 \mathrm{ppm}$.

The second peak of the gap voltage shows a similar behaviour to the discharge current amplitude (see Figure 5). Specifically, it shows a sharp increase for up to $600 \mathrm{ppm}$ water in the mixture, while for higher levels it approaches a constant value. This behaviour can be explained by the surface charge accumulation on the dielectrics during the breakdown. In particular, as the level of water increases in the mixture (up to $600 \mathrm{ppm}$ ), the amplitude of the discharge current increases but its pulse width becomes narrower (see Figure 4). Due to the narrower width, the total charge accumulation on the dielectrics and the shielding of the applied voltage decreases (see Figure 6, presenting the surface charge density on the dielectrics at different levels of water admixtures over a voltage cycle). For that reason, the gap voltage increases significantly. However, above $600 \mathrm{ppm}$ of water, the discharge current pulse amplitude, width 
and charge accumulation generally remain constant. This results in somewhat constant shielding and therefore, constant second peak of the gap voltage.

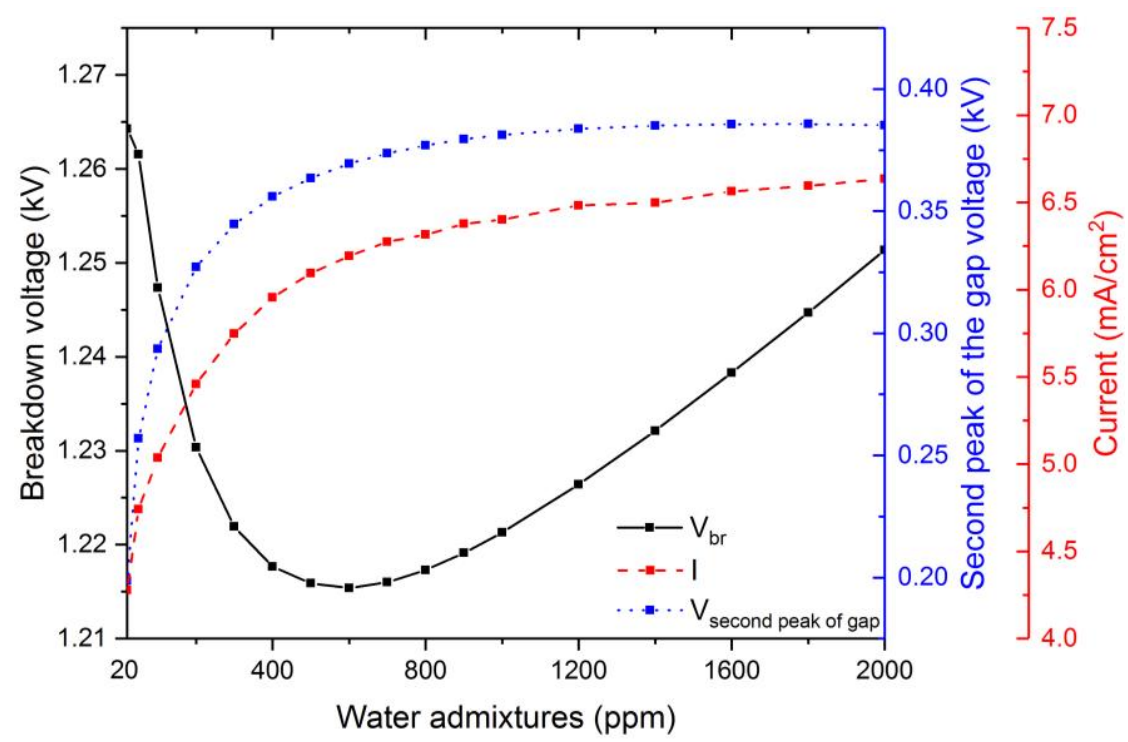

Figure 5: Simulation results of the breakdown voltage, second peak of the gap voltage and amplitude of the discharge current at different levels of water in a He/dry air (500 ppm) DBD. The amplitude and frequency of the sinusoidal applied voltage are $2.5 \mathrm{kV}$ peak to peak and 10 $\mathrm{kHz}$ respectively.

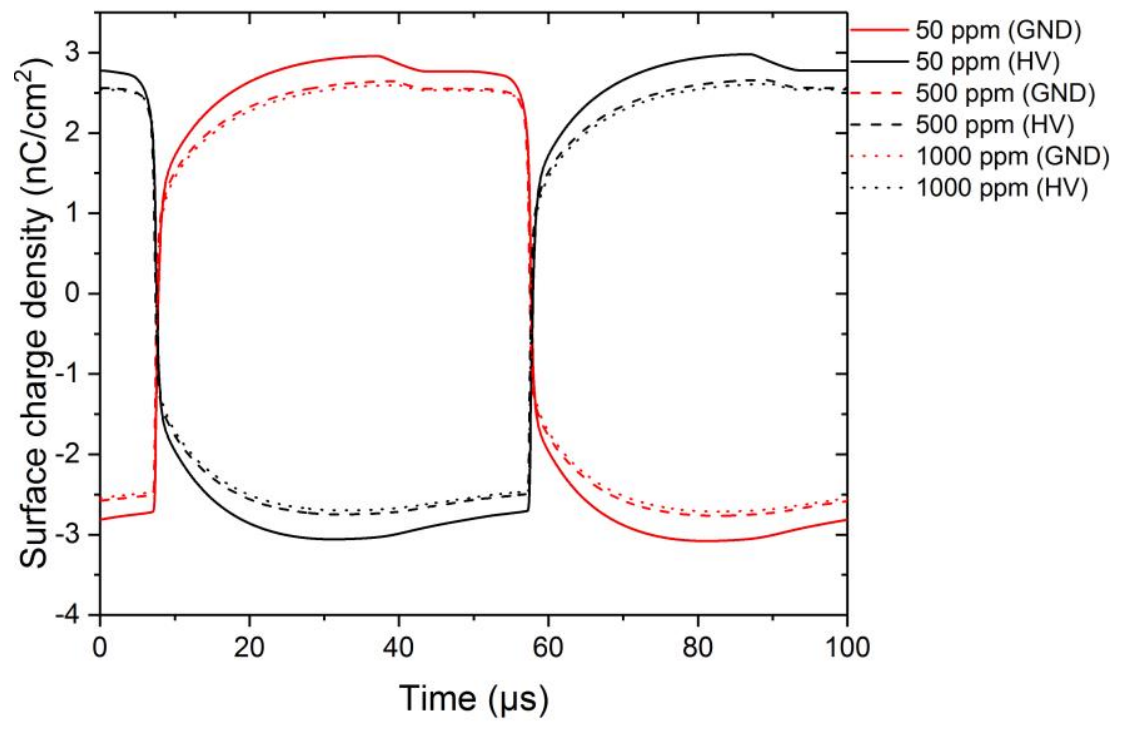

Figure 6: Simulation results of the surface charge density on the dielectrics at different levels of water admixtures $(50,500$ and $1000 \mathrm{ppm})$ over a voltage cycle. GND refers to the dielectric covering the ground electrode and HV to the dielectric covering the high voltage electrode.

\subsection{Effect of water admixtures on the ion composition of a He/dry air (500 ppm) DBD}

In Figure 7, the average concentrations of the positive ions during the breakdown are presented, for different levels of water admixtures (20 - $2000 \mathrm{ppm})$. As can be observed, the dominant positive ion from 20 to $100 \mathrm{ppm}$ of water is $\mathrm{H}_{2} \mathrm{O}^{+}$, while from $100-2000 \mathrm{ppm}$ it is $\mathrm{H}_{11} \mathrm{O}_{5}{ }^{+}$. It is noted that at $2000 \mathrm{ppm}$ of water, the concentrations of $\mathrm{H}_{11} \mathrm{O}_{5}{ }^{+}$and $\mathrm{H}_{13} \mathrm{O}_{6}{ }^{+}$coincide. At this level, the concentrations of $\mathrm{H}_{11} \mathrm{O}_{5}{ }^{+}$and $\mathrm{H}_{13} \mathrm{O}_{6}{ }^{+}$have a negative and positive slope respectively, indicating that $\mathrm{H}_{13} \mathrm{O}_{6}{ }^{+}$will become the dominant ion in the mixture after 2000 ppm. 
To analyze the evolution of positive ions concentrations, the most important reaction pathways for ion production are presented in the schematic diagram of Figure 8. It is noted that the simulation results shown that the relative intensities of the different electron sources do not change considerably in time. Furthermore, the analysis of the simulation results shown that Penning ionization processes (associated with $\mathrm{He}_{\mathrm{m}}$ ) are the most important reactions for ion production.

At low levels of water in the mixture (up to $50 \mathrm{ppm}$ ), $\mathrm{He}_{\mathrm{m}}$ species are mainly lost in the Penning ionization reactions 52, 59 and 115 (see Figure 10 that presents the most important reactions for electron production) for the production of nitrogen and oxygen positive ions. However, the nitrogen and oxygen ions are quickly converted to $\mathrm{H}_{2} \mathrm{O}^{+}$and $\mathrm{H}_{2} \mathrm{O}_{3}{ }^{+}$and for that reason are not the dominant ions, even at these low levels of water in the mixture. As the level of water further increases in the mixture, the amount of $\mathrm{He}_{\mathrm{m}}$ lost in Penning ionization reactions with $\mathrm{H}_{2} \mathrm{O}$ species increases (reactions 283, 285, 286, 287, 288 and 289, see Figure 10), and particularly through reaction 286 . For the above reasons, $\mathrm{H}_{2} \mathrm{O}^{+}$is the dominant ion in the range of $20-100 \mathrm{ppm}$. The concentration of $\mathrm{H}_{2} \mathrm{O}^{+}\left(\mathrm{OH}^{+}, \mathrm{H}^{+}\right.$and $\mathrm{HeH}^{+}$, the other ions produced through Penning ionization reactions of $\mathrm{He}_{\mathrm{m}}$ with water species), presents a maximum and then decreases as the level of water admixtures increases. This occurs due to the hydration of these species or their conversion to higher order cluster ions. In particular, above $\sim 90 \mathrm{ppm}$ of water in the mixture, $\mathrm{OH}^{+}$and $\mathrm{H}^{+}$are quickly converted to $\mathrm{H}_{2} \mathrm{O}^{+}$. Similarly, $\mathrm{H}_{2} \mathrm{O}^{+}$and $\mathrm{HeH}^{+}$, after 60 and $300 \mathrm{ppm}$ respectively are converted to $\mathrm{H}_{3} \mathrm{O}^{+}$. However, the concentration of $\mathrm{H}_{3} \mathrm{O}^{+}$does not become the dominant one at any level of water in the mixture, because it is immediately converted to $\mathrm{H}_{5} \mathrm{O}_{2}{ }^{+}$. Similar behavior is also observed for $\mathrm{H}_{5} \mathrm{O}_{2}{ }^{+}$and $\mathrm{H}_{7} \mathrm{O}_{3}{ }^{+}$. In particular, the $\mathrm{H}_{5} \mathrm{O}_{2}{ }^{+}$is immediately converted to $\mathrm{H}_{7} \mathrm{O}_{3}{ }^{+}$which it then immediately converted to $\mathrm{H}_{9} \mathrm{O}_{4}{ }^{+}$. As the level of water increases in the mixture (100-2000 ppm), the most dominant ion becomes $\mathrm{H}_{11} \mathrm{O}_{5}{ }^{+}$ due to the fast hydration of the lightest water clusters. Similar results were also observed in the global model [38,27].

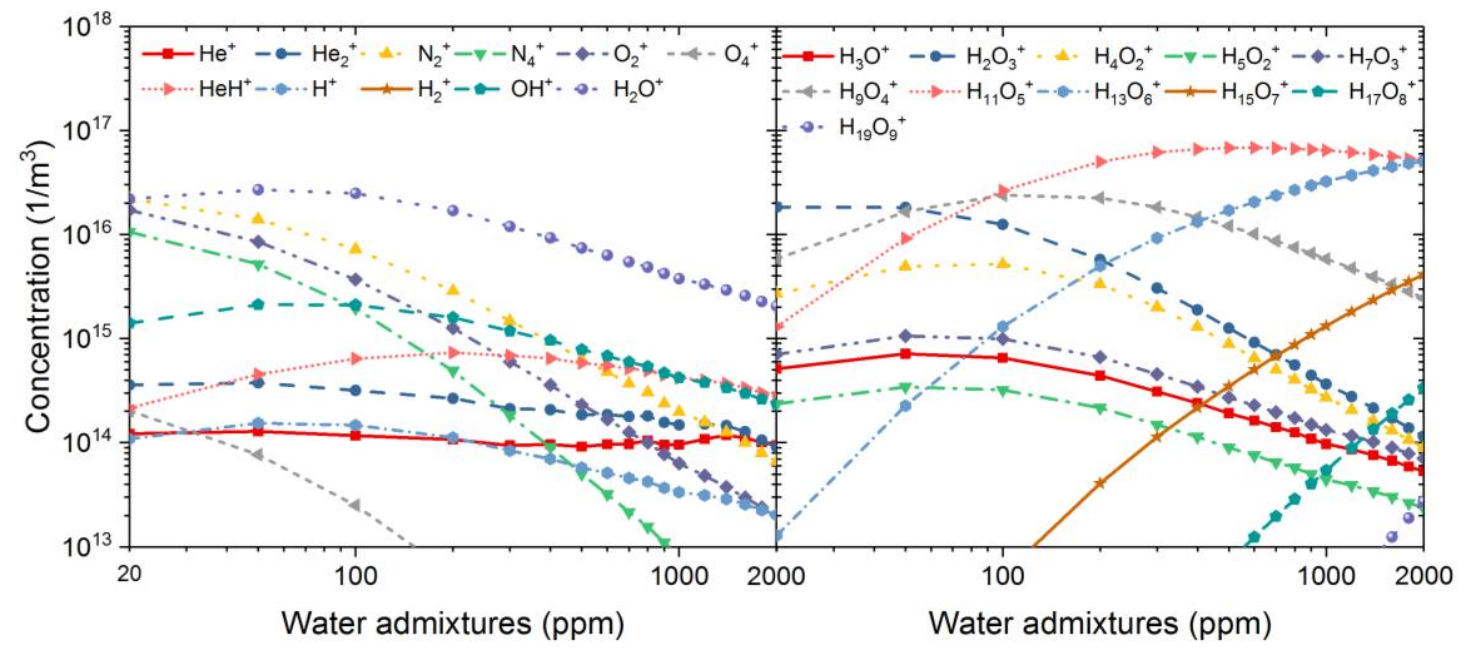

Figure 7: Average concentrations of the positive ions during the breakdown, for different levels of water admixtures in the helium/dry air (500 ppm) discharge. The amplitude and frequency of the sinusoidal applied voltage are $2.5 \mathrm{kV}$ peak to peak and $10 \mathrm{kHz}$ respectively. 


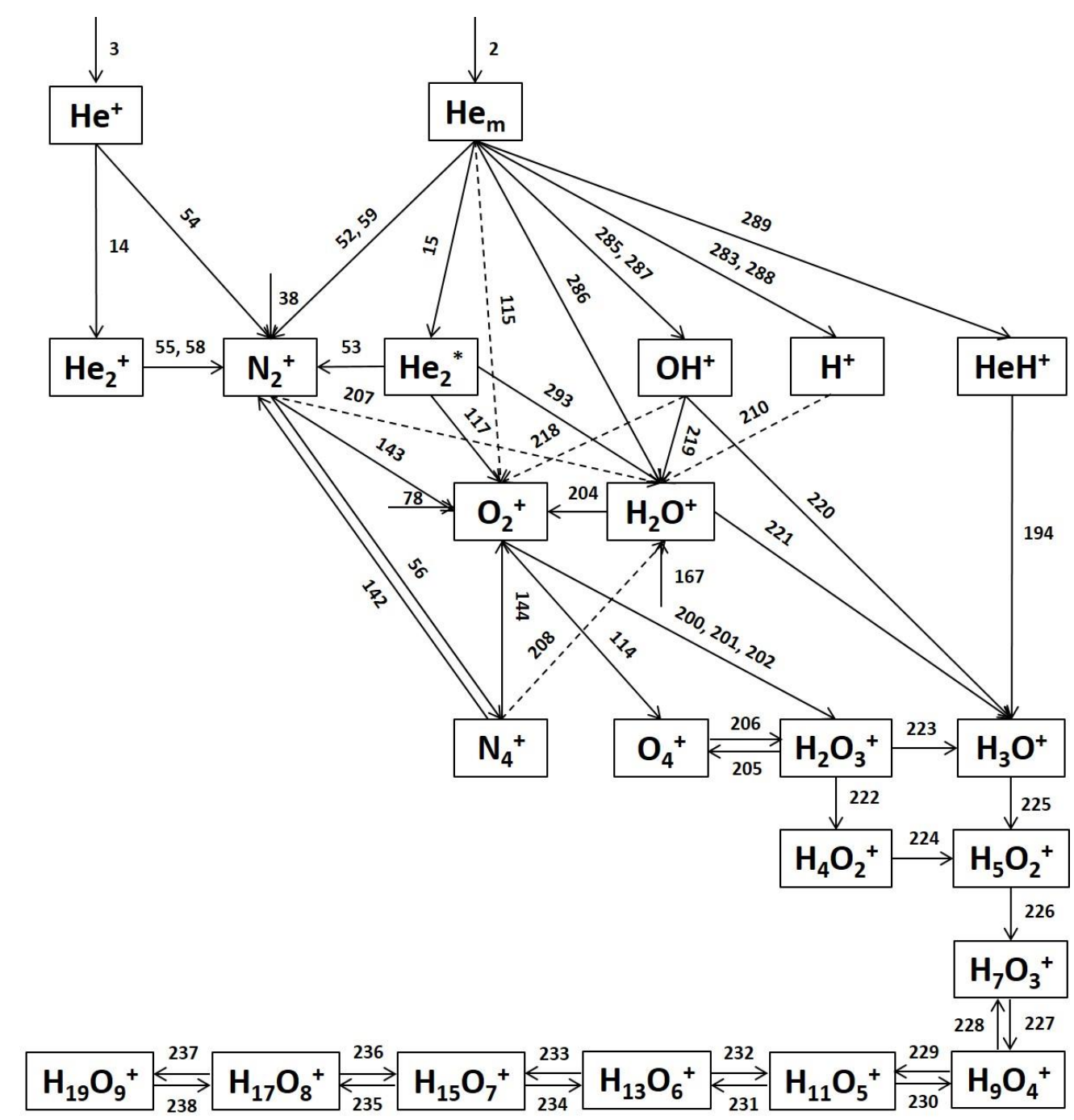

Figure 8: Schematic diagram of the most important reaction pathways for positive ion production.

The effect of water admixtures on the concentration of the negative charge species is presented in Figure 9. As it can be seen, electrons are the most important negative species in the mixture for the range of water admixtures considered in this study. The concentration of negative ions is at least one order of magnitude lower. Furthermore, it can be observed that the concentration of the negative ions $\mathrm{H}_{5} \mathrm{O}_{3}^{-}, \mathrm{H}_{2} \mathrm{O}_{2}^{-}, \mathrm{OH}^{-}, \mathrm{H}_{3} \mathrm{O}_{2}{ }^{-}$and $\mathrm{H}^{-}$exhibit an upward trend as the level of water increases in the mixture, that shows an increase of the electronegative character of the plasma. On the other hand, the oxygen negative ions $\left(\mathrm{O}^{-}\right.$and $\left.\mathrm{O}_{3}^{-}\right)$show a downward trend as the level of water increases in the mixture, similar to the results presented in [37], while the concentration of $\mathrm{O}_{2}^{-}$remains generally constant for the different levels of water in the mixture. 


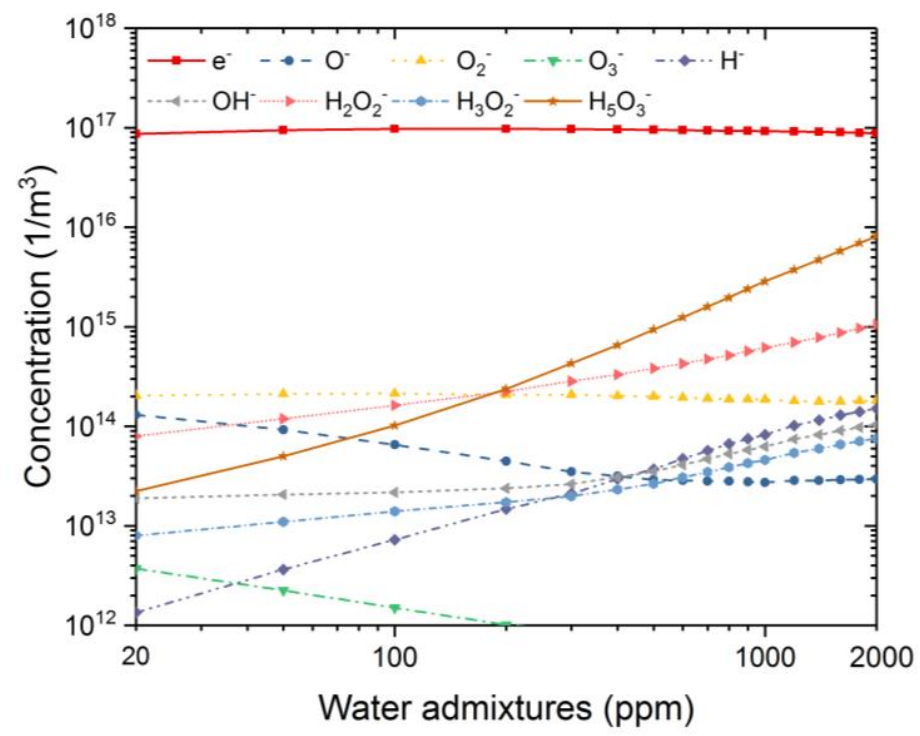

Figure 9: Average concentrations of the electrons and the negative ions during the breakdown, for different levels of water admixtures in the helium/dry air $(500 \mathrm{ppm})$ discharge. The amplitude and frequency of the sinusoidal applied voltage are $2.5 \mathrm{kV}$ peak to peak and $10 \mathrm{kHz}$ respectively.

As electrons are the most abundant in the mixture, it is important to investigate the reaction pathways behind their production and destruction. The average reaction rates for electron production during the breakdown are presented in Figure 10. As it can be seen, at low levels of water in the mixture (up to $50 \mathrm{ppm}$ ), the most important reactions for electron production are the Penning ionization of $\mathrm{He}_{\mathrm{m}}$ with $\mathrm{N}_{2}$ and $\mathrm{O}_{2}$ (reactions 52, 59 and 115), similar to prior work [46]. However, as the level of water increases in the mixture (>50 ppm), the loss of $\mathrm{He}_{\mathrm{m}}$ in Penning ionization reactions with $\mathrm{H}_{2} \mathrm{O}$ species increases and hence reaction $286\left(\mathrm{H}_{2} \mathrm{O}^{+}\right.$ production) becomes the dominant reaction for electron production. The other Penning ionization reactions of $\mathrm{He}_{\mathrm{m}}$ with $\mathrm{H}_{2} \mathrm{O}$ (for the production of $\mathrm{OH}^{+}, \mathrm{H}^{+}$and $\mathrm{HeH}^{+}$, reactions 287, 288 and 289) have a similar trend to reaction 286 but to a lesser extent. The increase of loss of $\mathrm{He}_{\mathrm{m}}$ species with water species (through Penning reactions) reduces the amount lost with the rest ground state species in the mixture (such as $\mathrm{He}, \mathrm{N}_{2}$ and $\mathrm{O}_{2}$ ). For that reason, the Penning ionization reactions 52, 59 and 115 (associated with $\mathrm{N}_{2}$ and $\mathrm{O}_{2}$ species) decrease as the level of water increases in the mixture. Similar behavior occurs for reactions 53 and 117, as $\mathrm{He}_{2}{ }^{*}$ is mainly produced through $\mathrm{He}_{\mathrm{m}}$ species and He species.

Regarding the direct ionization processes, it can be seen that the direct ionization of $\mathrm{He}$, $\mathrm{N}_{2}$ and $\mathrm{O}_{2}$ (reactions 3,38 and 78 respectively) present an almost constant value for the different levels of water in the mixture. Furthermore, these reactions are less important in comparison to the Penning ionization reactions (associated with $\mathrm{He}_{\mathrm{m}}$ species). On the other hand, as expected, the direct ionization of $\mathrm{H}_{2} \mathrm{O}$ (reaction 167) increases as the level of water increases. Finally, it is noted that only the detachment collisional reaction 188 approaches the contribution of reaction 286 (most important Penning ionization reaction of electron production) at high levels of water in the mixture (>1500 ppm). Similar trend is also present for the detachment collisional reaction 189 but to a lesser extent. 


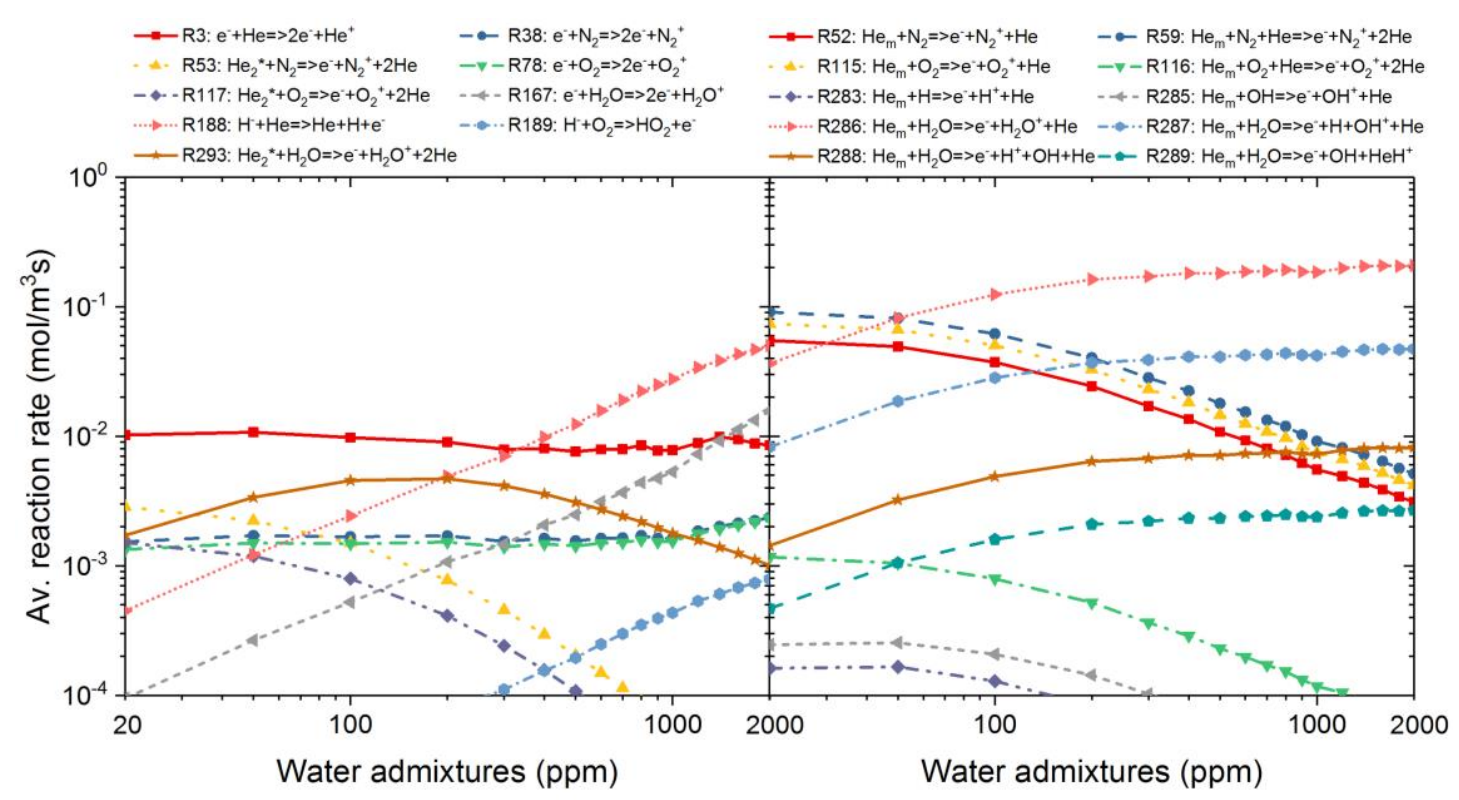

Figure 10: Simulation results of the average reaction rates of electron production during the breakdown, for different levels of water admixtures in the helium/dry air (500 ppm) discharge. The amplitude and frequency of the sinusoidal applied voltage are $2.5 \mathrm{kV}$ peak to peak and 10 $\mathrm{kHz}$ respectively.

The average reaction rates for electron destruction during the breakdown are presented in Figure 11. The most important reaction for electron destruction up to $70 \mathrm{ppm}$ of water admixtures, is the dissociative recombination of electrons with $\mathrm{H}_{9} \mathrm{O}_{4}{ }^{+}$positive ions (reaction 182), while from 70 and up to 1500 the dissociative recombination with $\mathrm{H}_{11} \mathrm{O}_{5}{ }^{+}$(reaction 183). As the level of water increases more than $1500 \mathrm{ppm}$, it can be observed that the dissociative attachment of electrons with $\mathrm{H}_{2} \mathrm{O}$ molecules (reaction 160, for the production of $\mathrm{H}^{-}$) becomes the dominant reaction for electron destruction. It is noted that $\mathrm{H}^{-}$is quickly converted to $\mathrm{OH}^{-}$(through reaction 211) which is then converted to $\mathrm{H}_{3} \mathrm{O}_{2}{ }^{-}$(through reaction 240) and which is finally converted to $\mathrm{H}_{5} \mathrm{O}_{3}{ }^{-}$(through the reaction 242). For that reason for high levels of water in the mixture, $\mathrm{H}_{5} \mathrm{O}_{3}{ }^{-}$ is the next most important negative species in the mixture after electrons (see Figure 9).

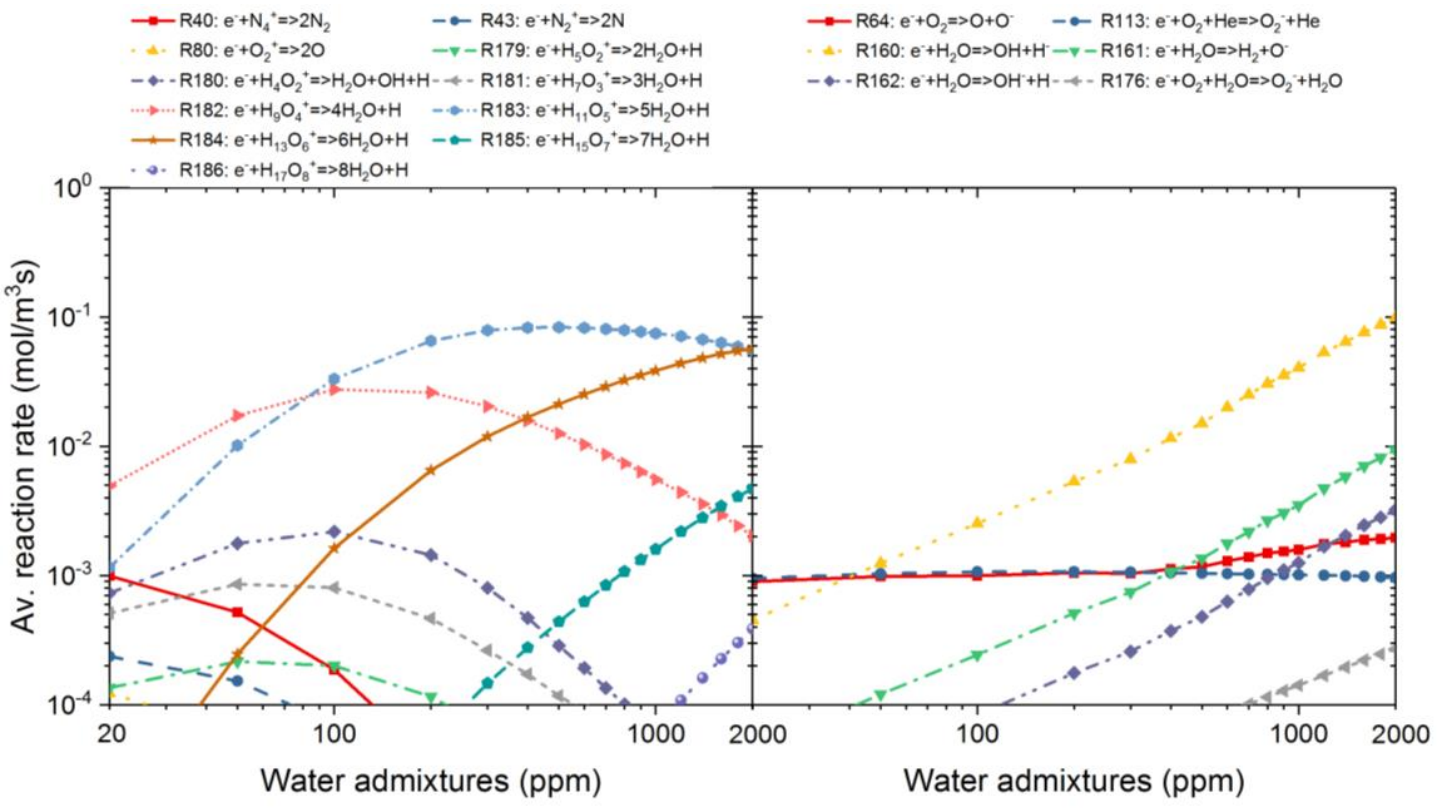

Figure 11: Simulation results of the average reaction rates of electron destruction during the breakdown, for different levels of water admixtures in the helium/dry air (500 ppm) discharge. 
The amplitude and frequency of the sinusoidal applied voltage are $2.5 \mathrm{kV}$ peak to peak and 10 $\mathrm{kHz}$ respectively.

\section{Conclusions}

In this study a one-dimensional plasma fluid model is used to investigate the effect of water admixtures on the evolution of a helium/dry air (500 ppm, 79\% $\mathrm{N}_{2}$ and $21 \% \mathrm{O}_{2}$ ) DBD. The level of water in the mixture is varied in the range of $20-2000 \mathrm{ppm}$. The simulation results show that water admixtures highly affect the discharge characteristics and the dominant ions in the mixture. In particular, the increase of water in the mixture benefits the $\mathrm{H}_{2} \mathrm{O}$-related reactions. This causes the discharge current peak to increase, and the discharge to ignite at lower voltages (up to $600 \mathrm{ppm}$ of water). However, the further increase of water (above $600 \mathrm{ppm}$ ) enhances the attachment of electrons with water molecules which causes the discharge to ignite at higher voltages. Despite the higher breakdown voltage, the discharge current peak remains almost constant, due to the high attachment of electrons with water molecules. Furthermore, the increase of water in the mixture causes the discharge current pulse width to become narrower. This reduces the total charge accumulation on the dielectrics and consequently the shielding of the applied voltage.

The simulation results show that the dominant ion for water admixtures in the range of 20 to $100 \mathrm{ppm}$ is $\mathrm{H}_{2} \mathrm{O}^{+}$. By further increasing the water in the mixture, the water ion clusters are quickly converted to heavier water ion clusters. For that reason, from $100 \mathrm{ppm}$ of water and up to $2000 \mathrm{ppm}$, the $\mathrm{H}_{11} \mathrm{O}_{5}{ }^{+}$is the most abundant ion in the mixture. The processes behind ion production and interaction are summarized in a schematic diagram. This diagram provides a simple yet complete picture for ion evolution and the dependence on the level of admixtures in the He discharge. Finally, from 20 to $2000 \mathrm{ppm}$ of water admixtures, the most important negative charge species are found to be electrons. It is also observed that as the level of water increases in the mixture the electronegative character of the plasma increases.

\section{Acknowledgment}

This project has received funding by the European Union Horizon 2020 Marie SkłodowskaCurie Actions Individual Fellowship (MSCA-IF-2015) under grant agreement number 703497.

\section{Appendix A}

Table A1: Rate coefficients for helium, nitrogen, oxygen and water reactions.

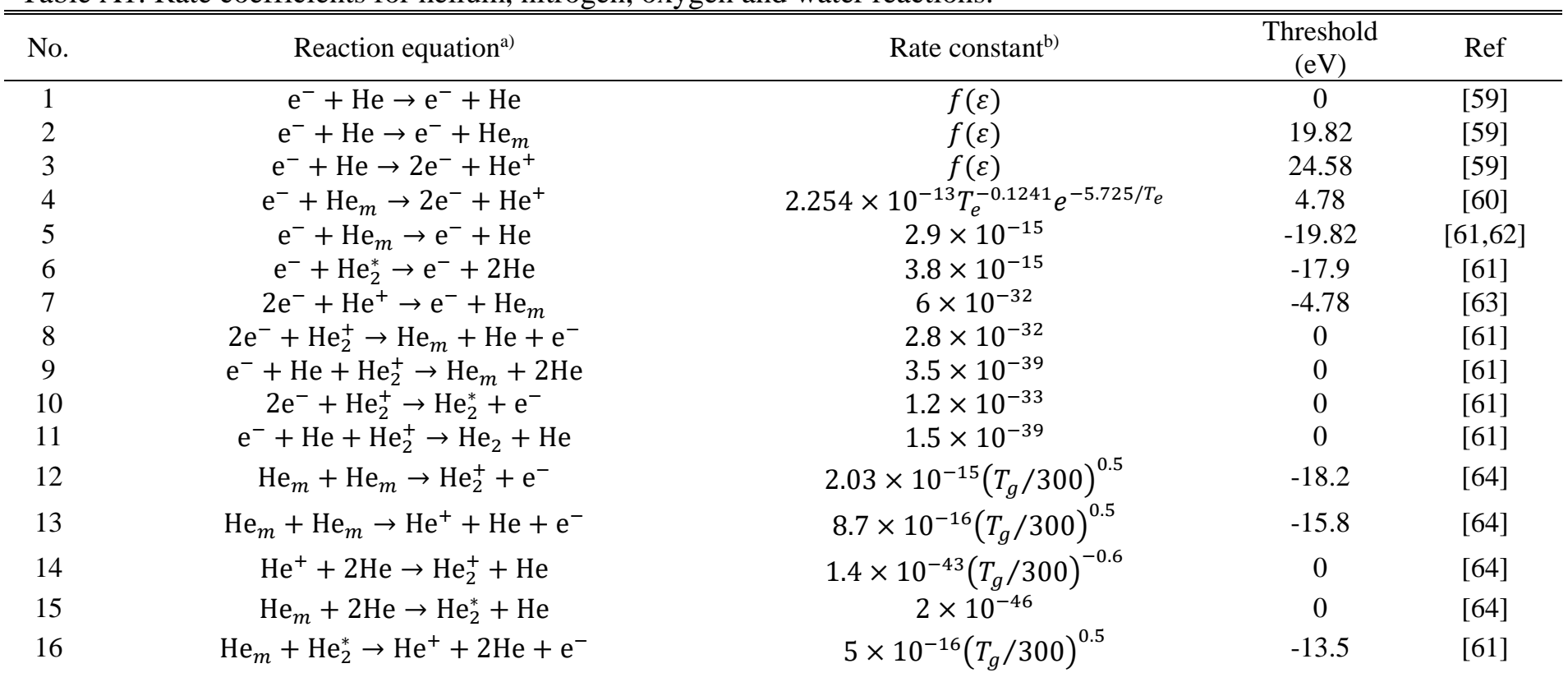




$$
\begin{gathered}
\mathrm{He}_{m}+\mathrm{He}_{2}^{*} \rightarrow \mathrm{He}_{2}^{+}+\mathrm{He}+\mathrm{e}^{-} \\
\mathrm{He}_{2}^{*}+\mathrm{He}_{2}^{*} \rightarrow \mathrm{He}^{+}+3 \mathrm{He}+\mathrm{e}^{-} \\
\mathrm{He}_{2}^{*}+\mathrm{He}_{2}^{*} \rightarrow \mathrm{He}_{2}^{+}+2 \mathrm{He}+\mathrm{e}^{-} \\
\mathrm{He}_{2}^{*}+\mathrm{He} \rightarrow 2 \mathrm{He}+\mathrm{He} \\
\mathrm{e}^{-}+\mathrm{He}+\mathrm{He}^{+} \rightarrow \mathrm{He}_{m}+\mathrm{He} \\
\mathrm{e}^{-}+\mathrm{He}_{2}^{+} \rightarrow \mathrm{He}+\mathrm{He}_{m} \\
\mathrm{He}_{m}+2 \mathrm{He} \rightarrow 3 \mathrm{He}^{-} \\
\mathrm{e}^{-}+\mathrm{He}_{2}^{*} \rightarrow \mathrm{He}_{2}^{+}+2 \mathrm{e}^{-}
\end{gathered}
$$

$\mathrm{e}^{-}+\mathrm{N}_{2} \rightarrow \mathrm{e}^{-}+\mathrm{N}_{2}(v=1$ to 10$)$

$$
\begin{gathered}
\mathrm{e}^{-}+\mathrm{N}_{2} \rightarrow \mathrm{e}^{-}+\mathrm{N}_{2}(\mathrm{~A}) \\
\mathrm{e}^{-}+\mathrm{N}_{2} \rightarrow \mathrm{e}^{-}+\mathrm{N}_{2}(\mathrm{~A}) \\
\mathrm{e}^{-}+\mathrm{N}_{2} \rightarrow \mathrm{e}^{-}+\mathrm{N}_{2}(\mathrm{~B}) \\
\mathrm{e}^{-}+\mathrm{N}_{2} \rightarrow \mathrm{e}^{-}+\mathrm{N}_{2}(\mathrm{~B}) \\
\mathrm{e}^{-}+\mathrm{N}_{2} \rightarrow \mathrm{e}^{-}+\mathrm{N}_{2}(\mathrm{~A}) \\
\mathrm{e}^{-}+\mathrm{N}_{2} \rightarrow \mathrm{e}^{-}+\mathrm{N}_{2}(\mathrm{~B}) \\
\mathrm{e}^{-}+\mathrm{N}_{2} \rightarrow \mathrm{e}^{-}+\mathrm{N}_{2}(\mathrm{a}) \\
\mathrm{e}^{-}+\mathrm{N}_{2} \rightarrow \mathrm{e}^{-}+\mathrm{N}_{2}(\mathrm{a}) \\
\mathrm{e}^{-}+\mathrm{N}_{2} \rightarrow \mathrm{e}^{-}+\mathrm{N}_{2}(\mathrm{a}) \\
\mathrm{e}^{-}+\mathrm{N}_{2} \rightarrow \mathrm{e}^{-}+\mathrm{N}_{2}(\mathrm{C}) \\
\mathrm{e}^{-}+\mathrm{N}_{2} \rightarrow \mathrm{e}^{-}+\mathrm{N}_{2}(\mathrm{C}) \\
\mathrm{e}^{-}+\mathrm{N}_{2} \rightarrow \mathrm{e}^{-}+\mathrm{N}_{2}(\mathrm{C}) \\
\mathrm{e}^{-}+\mathrm{N}_{2} \rightarrow 2 \mathrm{e}^{-}+\mathrm{N}_{2}^{+} \\
\mathrm{e}^{-}+\mathrm{N}_{2} \rightarrow \mathrm{e}^{-}+\mathrm{N}^{+} \mathrm{N} \\
\mathrm{e}^{-}+\mathrm{N}_{4}^{+} \rightarrow 2 \mathrm{~N}_{2} \\
2 \mathrm{e}^{-}+\mathrm{N}_{4}^{+} \rightarrow 2 \mathrm{~N}_{2}+\mathrm{e}^{-} \\
2 \mathrm{e}^{-}+\mathrm{N}_{2}^{+} \rightarrow \mathrm{e}^{-}+\mathrm{N}_{2} \\
\mathrm{e}^{-}+\mathrm{N}_{2}^{+} \rightarrow 2 \mathrm{~N}
\end{gathered}
$$$$
\mathrm{N}_{2}(\mathrm{~A})+\mathrm{N}_{2}(\mathrm{a}) \rightarrow \mathrm{e}^{-}+\mathrm{N}_{4}^{+}
$$$$
\mathrm{N}_{2}(\mathrm{a})+\mathrm{N}_{2} \text { (a) } \rightarrow \mathrm{e}^{-}+\mathrm{N}_{4}^{+}
$$$$
\mathrm{N}_{2}(\mathrm{~B})+\mathrm{N}_{2} \rightarrow \mathrm{N}_{2}+\mathrm{N}_{2} \text { (A) }
$$$$
\mathrm{N}_{2}(\mathrm{C})+\mathrm{N}_{2} \rightarrow \mathrm{N}_{2}+\mathrm{N}_{2} \text { (a) }
$$$$
\mathrm{N}_{2}(\mathrm{a}) \rightarrow \mathrm{N}_{2}+h v(117 \mathrm{~nm})
$$$$
\mathrm{N}_{2}(\mathrm{~A}) \rightarrow \mathrm{N}_{2}+h v(293 \mathrm{~nm})
$$$$
\mathrm{N}_{2}(\mathrm{~B}) \rightarrow \mathrm{N}_{2}(\mathrm{~A})+h v(1045 \mathrm{~nm})
$$$$
\mathrm{N}_{2}(\text { C }) \rightarrow \mathrm{N}_{2}(\mathrm{~B})+h v(336 \mathrm{~nm})
$$$$
\mathrm{He}_{m}+\mathrm{N}_{2} \rightarrow \mathrm{e}^{-}+\mathrm{N}_{2}^{+}+\mathrm{He}
$$$$
\mathrm{He}_{2}^{*}+\mathrm{N}_{2} \rightarrow \mathrm{e}^{-}+\mathrm{N}_{2}^{+}+2 \mathrm{He}
$$$$
\mathrm{He}^{+}+\mathrm{N}_{2} \rightarrow \mathrm{N}_{2}^{+}+\mathrm{He}
$$$$
\mathrm{He}_{2}^{+}+\mathrm{N}_{2} \rightarrow \mathrm{N}_{2}^{+}+2 \mathrm{He}
$$$$
\mathrm{N}_{2}^{+}+\mathrm{He}+\mathrm{N}_{2} \rightarrow \mathrm{N}_{4}^{+}+\mathrm{He}
$$$$
\mathrm{He}^{+}+\mathrm{N}_{2}+\mathrm{He} \rightarrow \mathrm{N}_{2}^{+}+2 \mathrm{He}
$$$$
\mathrm{He}_{2}^{+}+\mathrm{N}_{2}+\mathrm{He} \rightarrow \mathrm{N}_{2}^{+}+3 \mathrm{He}
$$$$
\mathrm{He}_{m}+\mathrm{N}_{2}+\mathrm{He} \rightarrow \mathrm{N}_{2}^{+}+2 \mathrm{He}+\mathrm{e}^{-}
$$$$
\mathrm{He}_{2}^{*}+\mathrm{N}_{2} \rightarrow 2 \mathrm{He}+\mathrm{N}_{2}
$$$$
\mathrm{N}_{2}^{+}+2 \mathrm{~N}_{2} \rightarrow \mathrm{N}_{4}^{+}+\mathrm{N}_{2}
$$$$
\mathrm{N}_{4}^{+}+\mathrm{N}_{2} \rightarrow \mathrm{N}_{2}^{+}+2 \mathrm{~N}_{2}
$$$$
\mathrm{e}^{-}+\mathrm{O}_{2} \rightarrow \mathrm{e}^{-}+\mathrm{O}_{2}(v=1 \text { to } 4)
$$$$
\mathrm{e}^{-}+\mathrm{O}_{2} \rightarrow \mathrm{O}+\mathrm{O}^{-}
$$$$
\mathrm{e}^{-}+\mathrm{O}_{2}(b) \rightarrow 0+\mathrm{O}^{-}
$$$$
\mathrm{e}^{-}+\mathrm{O}_{2}(a) \rightarrow 0+\mathrm{O}^{-}
$$$$
\mathrm{e}^{-}+\mathrm{O}_{2}(v) \rightarrow 0+0^{-}
$$$$
\mathrm{e}^{-}+\mathrm{O}_{2} \rightarrow \mathrm{e}^{-}+\mathrm{O}_{2}(a)
$$$$
\mathrm{e}^{-}+\mathrm{O}_{2}(a) \rightarrow \mathrm{e}^{-}+\mathrm{O}_{2}
$$

$$
\begin{gathered}
2 \times 10^{-15}\left(T_{g} / 300\right)^{0.5} \\
3 \times 10^{-16}\left(T_{g} / 300\right)^{0.5} \\
1.2 \times 10^{-15}\left(T_{g} / 300\right)^{0.5} \\
1.5 \times 10^{-21} \\
7.4 \times 10^{-47}\left(T_{e} / T_{g}\right)^{-2} \\
7.12 \times 10^{-21}\left(T_{e} / T_{g}\right)^{-1.5} \\
2 \times 10^{-46} \\
9.75 \times 10^{-16} T_{e}^{0.71} e^{-3.4 / T_{e}}
\end{gathered}
$$

1.1, 1.4, 1.7,

$$
2,2.2,2.5 \text {, }
$$

$f(\varepsilon)$

$f(\varepsilon)$

$f(\varepsilon)$

$f(\varepsilon)$

$f(\varepsilon)$

$f(\varepsilon)$

$f(\varepsilon)$

$f(\varepsilon)$

$f(\varepsilon)$

$f(\varepsilon)$

$f(\varepsilon)$

$f(\varepsilon)$

$f(\varepsilon)$

$$
1 \times 10^{-14} T_{e}^{0.5} e^{-16 / T_{e}}
$$

$3 \times 10^{-13}$

$3.17 \times 10^{-42}$

$3.17 \times 10^{-42}$

$2.54 \times 10^{-12} T_{e}^{-0.5}$

$5 \times 10^{-17}$

$2 \times 10^{-16}$

$3 \times 10^{-17}$

$1 \times 10^{-17}$

$1 \times 10^{2}$

$$
0.5
$$

$1.34 \times 10^{5}$

$2.45 \times 10^{7}$

$5 \times 10^{-17}$

$5 \times 10^{-17}$

$1.2 \times 10^{-15}$

$1.1 \times 10^{-15}$

$8.9 \times 10^{-42}\left(T_{g} / 300\right)^{-1.54}$

$1.1 \times 10^{-41}$

$1.6 \times 10^{-41}$

$3.3 \times 10^{-42}$

$1.5 \times 10^{-21}$

$5 \times 10^{-41}$

$2.5 \times 10^{-21}$

$f(\varepsilon)$

$f(\varepsilon)$

$f(\varepsilon)$

$f(\varepsilon)$

$f(\varepsilon)$

$f(\varepsilon)$

$f(\varepsilon)$

\section{7}

[61]

[61]

[64]

[67]

[67]

[67]

[67]

[67]

[67]

[67]

[67]

[67]

[67]

[68]

[69]

[60]

[70]

[50]

[71]

[71]

[72]

[73]

[73]

[73]

[60]

[60]

[74]

[74]

[74]

[74]

[74]

[75]

[35]

[76]

[76]

$0.19,0.38$, $0.6,0.8$ 


$$
\begin{aligned}
& \mathrm{e}^{-}+\mathrm{O}_{2} \rightarrow \mathrm{e}^{-}+\mathrm{O}_{2}(b) \\
& \mathrm{e}^{-}+\mathrm{O} \rightarrow \mathrm{e}^{-}+\mathrm{O}\left({ }^{1} D\right) \\
& \mathrm{e}^{-}+\mathrm{O} \rightarrow \mathrm{e}^{-}+\mathrm{O}\left({ }^{1} S\right) \\
& \mathrm{e}^{-}+\mathrm{O}_{2} \rightarrow \mathrm{e}^{-}+20 \\
& \mathrm{e}^{-}+\mathrm{O}_{2}(b) \rightarrow \mathrm{e}^{-}+\mathrm{O}\left({ }^{1} D\right)+\mathrm{O} \\
& \mathrm{e}^{-}+\mathrm{O}_{2} \rightarrow \mathrm{e}^{-}+\mathrm{O}+\mathrm{O}\left({ }^{1} D\right) \\
& \mathrm{e}^{-}+\mathrm{O}_{2} \rightarrow \mathrm{e}^{-}+\mathrm{O}+\mathrm{O}\left({ }^{1} S\right) \\
& \mathrm{e}^{-}+\mathrm{O}_{2}(a) \rightarrow 2 \mathrm{e}^{-}+\mathrm{O}_{2}^{+} \\
& \mathrm{e}^{-}+\mathrm{O}_{2} \rightarrow 2 \mathrm{e}^{-}+\mathrm{O}_{2}^{+} \\
& \mathrm{e}^{-}+\mathrm{O}_{3} \rightarrow \mathrm{e}^{-}+\mathrm{O}_{2}+\mathrm{O} \\
& \mathrm{e}^{-}+\mathrm{O}_{2}^{+} \rightarrow 20 \\
& \mathrm{e}^{-}+\mathrm{O}+\mathrm{O}_{2} \rightarrow \mathrm{O}^{-}+\mathrm{O}_{2} \\
& \mathrm{e}^{-}+\mathrm{O}_{2}+\mathrm{O}_{2} \rightarrow \mathrm{O}_{2}^{-}+\mathrm{O}_{2} \\
& \mathrm{e}^{-}+\mathrm{O}_{2}^{+}+\mathrm{O}_{2} \rightarrow 2 \mathrm{O}_{2} \\
& 2 \mathrm{e}^{-}+\mathrm{O}_{2}^{+} \rightarrow \mathrm{e}^{-}+\mathrm{O}_{2} \\
& \mathrm{O}^{-}+\mathrm{O}_{2}+\mathrm{O}_{2} \rightarrow \mathrm{O}_{3}^{-}+\mathrm{O}_{2} \\
& \mathrm{O}_{2}^{-}+\mathrm{O} \rightarrow \mathrm{O}^{-}+\mathrm{O}_{2} \\
& \mathrm{O}_{2}^{-}+\mathrm{O}_{3} \rightarrow \mathrm{O}_{3}^{-}+\mathrm{O}_{2} \\
& \mathrm{O}_{2}^{+}+\mathrm{O}_{3}^{-}+\mathrm{O}_{2} \rightarrow \mathrm{O}_{2}+\mathrm{O}_{3}+\mathrm{O}_{2} \\
& \mathrm{O}_{4}^{+}+\mathrm{O}^{-}+\mathrm{O}_{2} \rightarrow 2 \mathrm{O}_{2}+\mathrm{O}+\mathrm{O}_{2} \\
& \mathrm{O}_{4}^{+}+\mathrm{O}_{2}^{-}+\mathrm{O}_{2} \rightarrow 3 \mathrm{O}_{2}+\mathrm{O}_{2} \\
& \mathrm{O}_{4}^{+}+\mathrm{O}_{3}^{-}+\mathrm{O}_{2} \rightarrow 2 \mathrm{O}_{2}+\mathrm{O}_{3}+\mathrm{O}_{2} \\
& \mathrm{O}+\mathrm{O}^{-} \rightarrow \mathrm{e}^{-}+\mathrm{O}_{2} \\
& \mathrm{O}^{-}+\mathrm{O}_{2}(b) \rightarrow \mathrm{e}^{-}+\mathrm{O}_{2}+\mathrm{O} \\
& \mathrm{O}^{-}+\mathrm{O}_{2}(a) \rightarrow \mathrm{e}^{-}+\mathrm{O}_{3} \\
& \mathrm{O}_{3}^{-}+\mathrm{O} \rightarrow \mathrm{O}_{2}^{-}+\mathrm{O}_{2} \\
& \mathrm{O}_{4}^{+}+\mathrm{O} \rightarrow \mathrm{O}_{2}^{+}+\mathrm{O}_{3} \\
& \mathrm{O}_{4}^{+}+\mathrm{O}_{2} \rightarrow \mathrm{O}_{2}^{+}+2 \mathrm{O}_{2} \\
& \mathrm{O}\left({ }^{1} D\right)+\mathrm{O}_{2} \rightarrow \mathrm{O}_{2}+\mathrm{O} \\
& \mathrm{O}\left({ }^{1} D\right)+\mathrm{O}_{2} \rightarrow \mathrm{O}_{2}(a)+\mathrm{O} \\
& \mathrm{O}\left({ }^{1} D\right)+\mathrm{O}_{2} \rightarrow \mathrm{O}_{2}(b)+\mathrm{O} \\
& \mathrm{O}\left({ }^{1} S\right)+\mathrm{O}_{2}(a) \rightarrow \mathrm{O}+\mathrm{O}_{2} \\
& \mathrm{O}_{2}(b)+\mathrm{O}_{3} \rightarrow 2 \mathrm{O}_{2}+\mathrm{O} \\
& \mathrm{e}^{-}+\mathrm{O}_{4}^{+} \rightarrow 2 \mathrm{O}_{2} \\
& \mathrm{e}^{-}+\mathrm{O}+\mathrm{He} \rightarrow \mathrm{O}^{-}+\mathrm{He} \\
& \mathrm{e}^{-}+\mathrm{O}_{3}+\mathrm{He} \rightarrow \mathrm{O}_{3}^{-}+\mathrm{He} \\
& \mathrm{He}_{2}^{*}+\mathrm{O}_{2} \rightarrow 2 \mathrm{He}+\mathrm{O}_{2} \\
& \mathrm{O}_{2}(v)+\mathrm{M} \rightarrow \mathrm{O}_{2}+\mathrm{M} \\
& \mathrm{O}^{-}+\mathrm{O}_{2}+\mathrm{He} \rightarrow \mathrm{O}_{3}^{-}+\mathrm{He} \\
& \mathrm{O}_{2}^{+}+\mathrm{O}_{3}^{-}+\mathrm{He} \rightarrow \mathrm{O}_{2}+\mathrm{O}_{3}+\mathrm{He} \\
& \mathrm{O}_{4}^{+}+\mathrm{O}^{-}+\mathrm{He} \rightarrow 2 \mathrm{O}_{2}+\mathrm{O}+\mathrm{He} \\
& \mathrm{O}_{4}^{+}+\mathrm{O}_{2}^{-}+\mathrm{He} \rightarrow 3 \mathrm{O}_{2}+\mathrm{He} \\
& \mathrm{O}_{4}^{+}+\mathrm{O}_{3}^{-}+\mathrm{He} \rightarrow 2 \mathrm{O}_{2}+\mathrm{O}_{3}+\mathrm{He} \\
& \mathrm{e}^{-}+\mathrm{O}_{2}+\mathrm{He} \rightarrow \mathrm{He}+\mathrm{O}_{2}^{-} \\
& \mathrm{O}_{2}^{+}+\mathrm{O}_{2}+\mathrm{He} \rightarrow \mathrm{O}_{4}^{+}+\mathrm{He} \\
& \mathrm{He}_{m}+\mathrm{O}_{2} \rightarrow \mathrm{O}_{2}^{+}+\mathrm{He}+\mathrm{e}^{-} \\
& \mathrm{He}+\mathrm{He}_{m}+\mathrm{O}_{2} \rightarrow \mathrm{O}_{2}^{+}+2 \mathrm{He}+\mathrm{e}^{-} \\
& \mathrm{He}_{2}^{*}+\mathrm{O}_{2} \rightarrow \mathrm{O}_{2}^{+}+2 \mathrm{He}+\mathrm{e}^{-} \\
& \mathrm{O}_{2}+\mathrm{O}+\mathrm{He} \rightarrow \mathrm{O}_{3}+\mathrm{He}
\end{aligned}
$$

\begin{tabular}{|c|c|c|}
\hline$f(\varepsilon)$ & 1.627 & {$[67]$} \\
\hline$f(\varepsilon)$ & 1.968 & [78] \\
\hline$f(\varepsilon)$ & 4.192 & [59] \\
\hline$f(\varepsilon)$ & 6 & [67] \\
\hline$f(\varepsilon)$ & 6.77 & [77] \\
\hline$f(\varepsilon)$ & 8.4 & {$[67]$} \\
\hline$f(\varepsilon)$ & 9.97 & [67] \\
\hline$f(\varepsilon)$ & 11.1 & [77] \\
\hline$f(\varepsilon)$ & 12.1 & {$[67]$} \\
\hline $5.88 \times 10^{-15}$ & 0 & [79] \\
\hline $1.2 \times 10^{-14} T_{e}^{-0.7}$ & 0 & [80] \\
\hline $1 \times 10^{-43}$ & 0 & [81] \\
\hline $2.26 \times 10^{-42}\left(T_{g} / 300\right)^{-0.5}$ & 0 & {$[82]$} \\
\hline $2.49 \times 10^{-41}\left(T_{e}\right)^{-1.5}$ & 0 & [81] \\
\hline $7.18 \times 10^{-39}\left(T_{e}\right)^{-4.5}$ & 0 & [71] \\
\hline $1.1 \times 10^{-42}\left(T_{g} / 300\right)^{-1}$ & 0 & {$[51]$} \\
\hline $1.5 \times 10^{-16}\left(T_{g} / 300\right)^{0.5}$ & 0 & {$[80]$} \\
\hline $6 \times 10^{-16}\left(T_{g} / 300\right)^{0.5}$ & 0 & {$[80]$} \\
\hline $2 \times 10^{-37}\left(T_{g} / 300\right)^{-2.5}$ & 0 & {$[51,71]$} \\
\hline $2 \times 10^{-37}\left(T_{g} / 300\right)^{-2.5}$ & 0 & {$[51,71]$} \\
\hline $2 \times 10^{-37}\left(T_{g} / 300\right)^{-2.5}$ & 0 & {$[51,71]$} \\
\hline $2 \times 10^{-37}\left(T_{g} / 300\right)^{-2.5}$ & 0 & {$[51,71]$} \\
\hline $2 \times 10^{-16}\left(T_{g} / 300\right)^{0.5}$ & 0 & {$[80]$} \\
\hline $6.9 \times 10^{-16}\left(T_{g} / 300\right)^{0.5}$ & 0 & {$[80]$} \\
\hline $3 \times 10^{-16}\left(T_{g} / 300\right)^{0.5}$ & 0 & {$[80]$} \\
\hline $2.5 \times 10^{-16}\left(T_{g} / 300\right)^{0.5}$ & 0 & {$[80]$} \\
\hline $3 \times 10^{-16}$ & 0 & [71] \\
\hline $3.3 \times 10^{-12}\left(T_{g} / 300\right)^{-4} e^{\left(-5030 / T_{g}\right)}$ & 0 & {$[71]$} \\
\hline $4.8 \times 10^{-18} e^{\left(67 / T_{g}\right)}$ & 0 & {$[83]$} \\
\hline $1.6 \times 10^{-18} e^{\left(67 / T_{g}\right)}$ & 0 & {$[83]$} \\
\hline $2.56 \times 10^{-17} e^{\left(67 / T_{g}\right)}$ & 0 & {$[83]$} \\
\hline $1.1 \times 10^{-16}$ & 0 & {$[80]$} \\
\hline $7.33 \times 10^{-18}\left(T_{g} / 300\right)^{0.5}$ & 0 & {$[80]$} \\
\hline $2.25 \times 10^{-13} T_{e}^{-0.5}$ & 0 & [71] \\
\hline $1 \times 10^{-43}$ & 0 & [51] \\
\hline $1 \times 10^{-43}$ & 0 & [51] \\
\hline $1.5 \times 10^{-21}$ & 0 & {$[65]$} \\
\hline $1 \times 10^{-20}\left(T_{g} / 300\right)^{0.5}$ & 0 & {$[80]$} \\
\hline $1.1 \times 10^{-42}\left(T_{g} / 300\right)^{-1}$ & 0 & {$[51]$} \\
\hline $2 \times 10^{-37}\left(T_{g} / 300\right)^{-2.5}$ & 0 & {$[51,71]$} \\
\hline $2 \times 10^{-37}\left(T_{g} / 300\right)^{-2.5}$ & 0 & {$[51,71]$} \\
\hline $2 \times 10^{-37}\left(T_{g} / 300\right)^{-2.5}$ & 0 & {$[51,71]$} \\
\hline $2 \times 10^{-37}\left(T_{g} / 300\right)^{-2.5}$ & 0 & {$[51,71]$} \\
\hline $1 \times 10^{-43}$ & 0 & [84] \\
\hline $5.8 \times 10^{-43}\left(T_{g} / 300\right)^{-3.1}$ & 0 & {$[85]$} \\
\hline $2.54 \times 10^{-16}\left(T_{g} / 300\right)^{0.5}$ & 0 & {$[80]$} \\
\hline $1.6 \times 10^{-43}$ & 0 & {$[86]$} \\
\hline $1 \times 10^{-16}\left(T_{g} / 300\right)^{0.5}$ & 0 & {$[87]$} \\
\hline $1.1 \times 10^{-46} e^{\left(510 / T_{g}\right)}$ & 0 & [84] \\
\hline
\end{tabular}




\begin{tabular}{|c|c|}
\hline 119 & $\mathrm{He}_{2}^{+}+\mathrm{O}_{2} \rightarrow \mathrm{O}_{2}^{+}+2 \mathrm{He}$ \\
\hline 120 & $\mathrm{O}\left({ }^{1} D\right)+\mathrm{He} \rightarrow \mathrm{O}+\mathrm{He}$ \\
\hline 121 & $\mathrm{O}_{2}^{+}+\mathrm{O}^{-}+\mathrm{M} \rightarrow \mathrm{O}_{2}+\mathrm{O}+\mathrm{M}$ \\
\hline 122 & $\mathrm{O}_{2}^{+}+\mathrm{O}_{2}^{-}+\mathrm{M} \rightarrow 2 \mathrm{O}_{2}+\mathrm{M}$ \\
\hline 123 & $\mathrm{O}_{2}^{+}+\mathrm{O}^{-}+\mathrm{N}_{2} \rightarrow \mathrm{O}_{3}+\mathrm{N}_{2}$ \\
\hline 124 & $\mathrm{O}_{2}^{+}+\mathrm{O}_{3}^{-}+\mathrm{N}_{2} \rightarrow \mathrm{O}_{2}+\mathrm{O}_{3}+\mathrm{N}_{2}$ \\
\hline 125 & $\mathrm{O}_{4}^{+}+\mathrm{O}^{-}+\mathrm{N}_{2} \rightarrow 2 \mathrm{O}_{2}+\mathrm{O}+\mathrm{N}_{2}$ \\
\hline 126 & $\mathrm{O}_{4}^{+}+\mathrm{O}_{2}^{-}+\mathrm{N}_{2} \rightarrow 3 \mathrm{O}_{2}+\mathrm{N}_{2}$ \\
\hline 127 & $\mathrm{O}_{4}^{+}+\mathrm{O}_{3}^{-}+\mathrm{N}_{2} \rightarrow 2 \mathrm{O}_{2}+\mathrm{O}_{3}+\mathrm{N}_{2}$ \\
\hline 128 & $\mathrm{~N}_{2}^{+}+\mathrm{O}^{-}+\mathrm{O}_{2} \rightarrow \mathrm{N}_{2}+\mathrm{O}+\mathrm{O}_{2}$ \\
\hline 129 & $\mathrm{~N}_{2}^{+}+\mathrm{O}^{-}+\mathrm{N}_{2} \rightarrow \mathrm{N}_{2}+\mathrm{O}+\mathrm{N}_{2}$ \\
\hline 130 & $\mathrm{~N}_{2}^{+}+\mathrm{O}_{2}^{-}+\mathrm{O}_{2} \rightarrow \mathrm{N}_{2}+\mathrm{O}_{2}+\mathrm{O}_{2}$ \\
\hline 131 & $\mathrm{~N}_{2}^{+}+\mathrm{O}_{2}^{-}+\mathrm{N}_{2} \rightarrow \mathrm{N}_{2}+\mathrm{O}_{2}+\mathrm{N}_{2}$ \\
\hline 132 & $\mathrm{~N}_{2}^{+}+\mathrm{O}_{2}+\mathrm{e}^{-} \rightarrow \mathrm{O}_{2}+\mathrm{N}_{2}$ \\
\hline 133 & $\mathrm{O}_{2}^{+}+\mathrm{N}_{2}+\mathrm{e}^{-} \rightarrow \mathrm{O}_{2}+\mathrm{N}_{2}$ \\
\hline 134 & $\mathrm{O}_{2}+\mathrm{N}+\mathrm{N} \rightarrow \mathrm{O}_{2}+\mathrm{N}_{2}$ \\
\hline 135 & $\mathrm{O}+\mathrm{O}_{2}+\mathrm{N}_{2} \rightarrow \mathrm{O}_{3}+\mathrm{N}_{2}$ \\
\hline 136 & $\mathrm{O}+\mathrm{O}+\mathrm{N}_{2} \rightarrow \mathrm{O}_{2}+\mathrm{N}_{2}$ \\
\hline 137 & $\mathrm{O}+\mathrm{O}+\mathrm{N} \rightarrow \mathrm{O}_{2}+\mathrm{N}$ \\
\hline 138 & $\mathrm{O}_{3}+\mathrm{N}_{2} \rightarrow \mathrm{O}+\mathrm{O}_{2}+\mathrm{N}_{2}$ \\
\hline 139 & $\mathrm{O}\left({ }^{1} S\right)+\mathrm{N}_{2} \rightarrow \mathrm{O}+\mathrm{N}_{2}$ \\
\hline 140 & $\mathrm{O}\left({ }^{1} D\right)+\mathrm{N}_{2} \rightarrow \mathrm{O}+\mathrm{N}_{2}$ \\
\hline 141 & $\mathrm{~N}_{4}^{+}+\mathrm{O}\left({ }^{1} D\right) \rightarrow \mathrm{O}+\mathrm{N}_{2}+\mathrm{N}_{2}^{+}$ \\
\hline 142 & $\mathrm{~N}_{4}^{+}+\mathrm{O}_{2} \rightarrow \mathrm{O}_{2}+\mathrm{N}_{2}+\mathrm{N}_{2}^{+}$ \\
\hline 143 & $\mathrm{~N}_{2}^{+}+\mathrm{O}_{2} \rightarrow \mathrm{N}_{2}+\mathrm{O}_{2}^{+}$ \\
\hline 144 & $\mathrm{~N}_{4}^{+}+\mathrm{O}_{2} \rightarrow 2 \mathrm{~N}_{2}+\mathrm{O}_{2}^{+}$ \\
\hline 145 & $\mathrm{O}_{4}^{+}+\mathrm{N}_{2} \rightarrow \mathrm{O}_{2}+\mathrm{N}_{2}+\mathrm{O}_{2}^{+}$ \\
\hline 146 & $\mathrm{O}^{-}+\mathrm{O}_{2}+\mathrm{N}_{2} \rightarrow \mathrm{N}_{2}+\mathrm{O}_{3}^{-}$ \\
\hline 147 & $\mathrm{e}^{-}+\mathrm{O}_{2}+\mathrm{N}_{2} \rightarrow \mathrm{N}_{2}+\mathrm{O}_{2}^{-}$ \\
\hline 148 & $\mathrm{e}^{-}+\mathrm{O}+\mathrm{N}_{2} \rightarrow \mathrm{N}_{2}+\mathrm{O}^{-}$ \\
\hline 149 & $\mathrm{O}_{2}^{-}+\mathrm{N}_{2}(\mathrm{~A}) \rightarrow \mathrm{e}^{-}+\mathrm{O}_{2}+\mathrm{N}_{2}$ \\
\hline 150 & $\mathrm{O}_{2}^{-}+\mathrm{N}_{2}(\mathrm{~B}) \rightarrow \mathrm{e}^{-}+\mathrm{O}_{2}+\mathrm{N}_{2}$ \\
\hline 151 & $\mathrm{O}^{-}+\mathrm{N}_{2}(\mathrm{~A}) \rightarrow \mathrm{e}^{-}+\mathrm{O}+\mathrm{N}_{2}$ \\
\hline 152 & $\mathrm{O}^{-}+\mathrm{N}_{2}(\mathrm{~B}) \rightarrow \mathrm{e}^{-}+\mathrm{O}+\mathrm{N}_{2}$ \\
\hline 153 & $\mathrm{~N}_{2}(\mathrm{~A})+\mathrm{O}_{2} \rightarrow 20+\mathrm{N}_{2}$ \\
\hline 154 & $\mathrm{~N}_{2}(\mathrm{~A})+\mathrm{O}_{2} \rightarrow \mathrm{O}_{2}(a)+\mathrm{N}_{2}$ \\
\hline 155 & $\mathrm{~N}_{2}(\mathrm{~A})+\mathrm{O} \rightarrow \mathrm{O}\left({ }^{1} S\right)+\mathrm{N}_{2}$ \\
\hline 156 & $\mathrm{~N}_{2}(\mathrm{~B})+\mathrm{O}_{2} \rightarrow 2 \mathrm{O}+\mathrm{N}_{2}$ \\
\hline 157 & $\mathrm{~N}_{2}(\mathrm{a})+\mathrm{O}_{2} \rightarrow 2 \mathrm{O}+\mathrm{N}_{2}$ \\
\hline 158 & $\mathrm{~N}_{2}(\mathrm{C})+\mathrm{O}_{2} \rightarrow \mathrm{O}+\mathrm{O}\left({ }^{1} S\right)+\mathrm{N}_{2}$ \\
\hline 159 & $\mathrm{e}^{-}+\mathrm{H}_{2} \mathrm{O} \rightarrow \mathrm{e}^{-}+\mathrm{H}_{2} \mathrm{O}$ \\
\hline 160 & $\mathrm{e}^{-}+\mathrm{H}_{2} \mathrm{O} \rightarrow \mathrm{OH}+\mathrm{H}^{-}$ \\
\hline 161 & $\mathrm{e}^{-}+\mathrm{H}_{2} \mathrm{O} \rightarrow \mathrm{H}_{2}+\mathrm{O}^{-}$ \\
\hline 162 & $\mathrm{e}^{-}+\mathrm{H}_{2} \mathrm{O} \rightarrow \mathrm{H}+\mathrm{OH}^{-}$ \\
\hline 163 & $\mathrm{e}^{-}+\mathrm{H}_{2} \mathrm{O} \rightarrow \mathrm{e}^{-}+\mathrm{H}+\mathrm{OH}$ \\
\hline 164 & $\mathrm{e}^{-}+\mathrm{H}_{2} \mathrm{O} \rightarrow \mathrm{e}^{-}+\mathrm{H}_{2}+\mathrm{O}\left({ }^{1} D\right)$ \\
\hline 165 & $\mathrm{e}^{-}+\mathrm{H}_{2} \rightarrow \mathrm{e}^{-}+2 \mathrm{H}$ \\
\hline 166 & $\mathrm{e}^{-}+\mathrm{H}_{2} \mathrm{O} \rightarrow \mathrm{e}^{-}+\mathrm{H}+\mathrm{OH}(\mathrm{A})$ \\
\hline 167 & $\mathrm{e}^{-}+\mathrm{H}_{2} \mathrm{O} \rightarrow 2 \mathrm{e}^{-}+\mathrm{H}_{2} \mathrm{O}^{+}$ \\
\hline 168 & $\mathrm{e}^{-}+\mathrm{H} \rightarrow 2 \mathrm{e}^{-}+\mathrm{H}^{+}$ \\
\hline 169 & $\mathrm{e}^{-}+\mathrm{H}_{2} \rightarrow 2 \mathrm{e}^{-}+\mathrm{H}_{2}^{+}$ \\
\hline
\end{tabular}

\begin{tabular}{|c|c|c|}
\hline $1 \times 10^{-15}\left(T_{g} / 300\right)^{0.5}$ & 0 & {$[88]$} \\
\hline $1 \times 10^{-19}$ & 0 & {$[80]$} \\
\hline $2 \times 10^{-37}\left(T_{g} / 300\right)^{-2.5}$ & 0 & {$[71,35]$} \\
\hline $2 \times 10^{-37}\left(T_{g} / 300\right)^{-2.5}$ & 0 & {$[71,35]$} \\
\hline $2 \times 10^{-37}\left(T_{g} / 300\right)^{-2.5}$ & 0 & {$[71,35]$} \\
\hline $1 \times 10^{-37}\left(T_{g} / 300\right)^{-2.5}$ & 0 & {$[71,35]$} \\
\hline $1 \times 10^{-37}\left(T_{g} / 300\right)^{-2.5}$ & 0 & {$[71,35]$} \\
\hline $1 \times 10^{-37}\left(T_{g} / 300\right)^{-2.5}$ & 0 & {$[71,35]$} \\
\hline $1 \times 10^{-37}\left(T_{g} / 300\right)^{-2.5}$ & 0 & {$[71,35]$} \\
\hline $2 \times 10^{-37}\left(T_{g} / 300\right)^{-2.5}$ & 0 & {$[71,35]$} \\
\hline $2 \times 10^{-37}\left(T_{g} / 300\right)^{-2.5}$ & 0 & {$[71,35]$} \\
\hline $2 \times 10^{-37}\left(T_{g} / 300\right)^{-2.5}$ & 0 & {$[71,35]$} \\
\hline $2 \times 10^{-37}\left(T_{g} / 300\right)^{-2.5}$ & 0 & {$[71,35]$} \\
\hline $6 \times 10^{-39}\left(T_{e} / T_{g}\right)^{-1.5}$ & 0 & {$[35]$} \\
\hline $6 \times 10^{-39}\left(T_{e} / T_{g}\right)^{-1.5}$ & 0 & {$[35]$} \\
\hline $3.9 \times 10^{-45}$ & 0 & {$[35]$} \\
\hline $1.1 \times 10^{-46} \exp \left(510 / T_{g}\right)$ & 0 & {$[35]$} \\
\hline $6.49 \times 10^{-47} \exp \left(1039 / T_{g}\right)$ & 0 & {$[35]$} \\
\hline $3.2 \times 10^{-45}\left(T_{g} / 300\right)^{-0.41}$ & 0 & {$[35]$} \\
\hline $1.6 \times 10^{-15} \exp \left(-11400 / T_{g}\right)$ & 0 & {$[35]$} \\
\hline $5 \times 10^{-23}$ & 0 & [35] \\
\hline $1.8 \times 10^{-17} \exp \left(107 / T_{q}\right)$ & 0 & {$[35]$} \\
\hline $1 \times 10^{-16}$ & 0 & [35] \\
\hline $2.5 \times 10^{-16}$ & 0 & [35] \\
\hline $1.04 \times 10^{-15} T_{g}^{-0.5}$ & 0 & [89] \\
\hline $4 \times 10^{-16^{y}}$ & 0 & [90] \\
\hline $1 \times 10^{-11}\left(T_{g} / 300\right)^{-4.2} \exp \left(-5400 / T_{g}\right)$ & 0 & {$[35]$} \\
\hline $1 \times 10^{-42}\left(T_{g} / 300\right)^{-1}$ & 0 & {$[71]$} \\
\hline $1.24 \times 10^{-43}\left(T_{g} / 300\right)^{-0.5}$ & 0 & {$[51]$} \\
\hline $1 \times 10^{-43}$ & 0 & [51] \\
\hline $2.1 \times 10^{-15}$ & 0 & [72] \\
\hline $2.5 \times 10^{-15}$ & 0 & [71] \\
\hline $2.2 \times 10^{-15}$ & 0 & {$[72]$} \\
\hline $1.9 \times 10^{-15}$ & 0 & [71] \\
\hline $1.7 \times 10^{-18}$ & 0 & [72] \\
\hline $7.5 \times 10^{-19}$ & 0 & [72] \\
\hline $2.3 \times 10^{-17}$ & 0 & [72] \\
\hline $1.1 \times 10^{-16}$ & 0 & {$[72]$} \\
\hline $2.8 \times 10^{-17}$ & 0 & [72] \\
\hline $3 \times 10^{-16}$ & 0 & {$[72]$} \\
\hline$f(\varepsilon)$ & 0 & [59] \\
\hline$f(\varepsilon)$ & 0 & [59] \\
\hline$f(\varepsilon)$ & 0 & [59] \\
\hline$f(\varepsilon)$ & 0 & [59] \\
\hline$f(\varepsilon)$ & 7 & [59] \\
\hline$f(\varepsilon)$ & 7.4 & [91] \\
\hline$f(\varepsilon)$ & 8.9 & [92] \\
\hline$f(\varepsilon)$ & 9 & [92] \\
\hline$f(\varepsilon)$ & 12.61 & [59] \\
\hline$f(\varepsilon)$ & 13.6 & [67] \\
\hline$f(\varepsilon)$ & 15.4 & [67] \\
\hline
\end{tabular}




$$
\begin{aligned}
& \mathrm{e}^{-}+\mathrm{OH} \rightarrow \mathrm{e}^{-}+\mathrm{O}+\mathrm{H} \\
& \mathrm{e}^{-}+\mathrm{OH} \rightarrow 2 \mathrm{e}^{-}+\mathrm{OH}^{+} \\
& \mathrm{e}^{-}+\mathrm{HO}_{2} \rightarrow \mathrm{e}^{-}+\mathrm{O}_{2}+\mathrm{H} \\
& \mathrm{e}^{-}+\mathrm{H}_{2} \mathrm{O}_{2} \rightarrow \mathrm{e}^{-}+2 \mathrm{OH} \\
& \mathrm{e}^{-}+\mathrm{H}_{2} \mathrm{O}_{2} \rightarrow \mathrm{e}^{-}+\mathrm{HO}_{2}+\mathrm{H} \\
& \mathrm{e}^{-}+\mathrm{OH}+\mathrm{He} \rightarrow \mathrm{He}+\mathrm{OH}^{-} \\
& \mathrm{e}^{-}+\mathrm{O}_{2}+\mathrm{H}_{2} \mathrm{O} \rightarrow \mathrm{O}_{2}^{-}+\mathrm{H}_{2} \mathrm{O} \\
& \mathrm{e}^{-}+\mathrm{H}_{2} \mathrm{O}_{2} \rightarrow \mathrm{H}_{2} \mathrm{O}+\mathrm{O}^{-} \\
& \mathrm{e}^{-}+\mathrm{H}_{2} \mathrm{O}_{2} \rightarrow \mathrm{OH}+\mathrm{OH}^{-} \\
& \mathrm{e}^{-}+\mathrm{H}_{5} \mathrm{O}_{2}^{+} \rightarrow 2 \mathrm{H}_{2} \mathrm{O}+\mathrm{H} \\
& \mathrm{e}^{-}+\mathrm{H}_{4} \mathrm{O}_{2}^{+} \rightarrow \mathrm{H}_{2} \mathrm{O}+\mathrm{OH}+\mathrm{H} \\
& \mathrm{e}^{-}+\mathrm{H}_{7} \mathrm{O}_{3}^{+} \rightarrow 3 \mathrm{H}_{2} \mathrm{O}+\mathrm{H} \\
& \mathrm{e}^{-}+\mathrm{H}_{9} \mathrm{O}_{4}^{+} \rightarrow 4 \mathrm{H}_{2} \mathrm{O}+\mathrm{H} \\
& \mathrm{e}^{-}+\mathrm{H}_{11} \mathrm{O}_{5}^{+} \rightarrow 5 \mathrm{H}_{2} \mathrm{O}+\mathrm{H} \\
& \mathrm{e}^{-}+\mathrm{H}_{13} \mathrm{O}_{6}^{+} \rightarrow 6 \mathrm{H}_{2} \mathrm{O}+\mathrm{H} \\
& \mathrm{e}^{-}+\mathrm{H}_{15} \mathrm{O}_{7}^{+} \rightarrow 7 \mathrm{H}_{2} \mathrm{O}+\mathrm{H} \\
& \mathrm{e}^{-}+\mathrm{H}_{17} \mathrm{O}_{8}^{+} \rightarrow 8 \mathrm{H}_{2} \mathrm{O}+\mathrm{H} \\
& \mathrm{e}^{-}+\mathrm{H}_{19} \mathrm{O}_{9}^{+} \rightarrow 9 \mathrm{H}_{2} \mathrm{O}+\mathrm{H} \\
& \mathrm{H}^{-}+\mathrm{He} \rightarrow \mathrm{He}+\mathrm{H}+\mathrm{e}^{-} \\
& \mathrm{H}^{-}+\mathrm{O}_{2} \rightarrow \mathrm{HO}_{2}+\mathrm{e}^{-} \\
& \mathrm{He}^{+}+\mathrm{H}_{2} \mathrm{O} \rightarrow \mathrm{H}^{+}+\mathrm{OH}+\mathrm{He} \\
& \mathrm{He}^{+}+\mathrm{H}_{2} \mathrm{O} \rightarrow \mathrm{OH}^{+}+\mathrm{H}+\mathrm{He} \\
& \mathrm{He}^{+}+\mathrm{H}_{2} \mathrm{O} \rightarrow \mathrm{H}_{2} \mathrm{O}^{+}+\mathrm{He} \\
& \mathrm{HeH}^{+}+\mathrm{H} \rightarrow \mathrm{H}_{2}^{+}+\mathrm{He} \\
& \mathrm{HeH}^{+}+\mathrm{H}_{2} \mathrm{O} \rightarrow \mathrm{H}_{3} \mathrm{O}^{+}+\mathrm{He} \\
& \mathrm{He}_{2}^{+}+\mathrm{H}_{2} \mathrm{O} \rightarrow \mathrm{HeH}^{+}+\mathrm{He}+\mathrm{OH}(\mathrm{A}) \\
& \mathrm{He}_{2}^{+}+\mathrm{H}_{2} \mathrm{O} \rightarrow \mathrm{OH}^{+}+\mathrm{H}+2 \mathrm{He} \\
& \mathrm{He}_{2}^{+}+\mathrm{H}_{2} \mathrm{O} \rightarrow \mathrm{H}^{+}+\mathrm{OH}+2 \mathrm{He} \\
& \mathrm{He}_{2}^{+}+\mathrm{H}_{2} \mathrm{O} \rightarrow \mathrm{HeH}^{+}+\mathrm{OH}+\mathrm{He} \\
& \mathrm{He}_{2}^{+}+\mathrm{H}_{2} \mathrm{O} \rightarrow \mathrm{H}_{2}^{+}+\mathrm{O}+2 \mathrm{He} \\
& \mathrm{O}_{2}^{+}+\mathrm{H}_{2} \mathrm{O}+\mathrm{N}_{2} \rightarrow \mathrm{H}_{2} \mathrm{O}_{3}^{+}+\mathrm{N}_{2} \\
& \mathrm{O}_{2}^{+}+\mathrm{H}_{2} \mathrm{O}+\mathrm{He} \rightarrow \mathrm{H}_{2} \mathrm{O}_{3}^{+}+\mathrm{He} \\
& \mathrm{O}_{2}^{+}+\mathrm{H}_{2} \mathrm{O}+\mathrm{O}_{2} \rightarrow \mathrm{H}_{2} \mathrm{O}_{3}^{+}+\mathrm{O}_{2}
\end{aligned}
$$$$
\mathrm{O}_{4}^{+}+\mathrm{H}_{2} \mathrm{O}+\mathrm{N}_{2} \rightarrow \mathrm{H}_{2} \mathrm{O}_{3}^{+}+\mathrm{O}_{2}+\mathrm{N}_{2}
$$$$
\mathrm{H}_{2} \mathrm{O}^{+}+\mathrm{O}_{2} \rightarrow \mathrm{O}_{2}^{+}+\mathrm{H}_{2} \mathrm{O}
$$$$
\mathrm{H}_{2} \mathrm{O}_{3}^{+}+\mathrm{O}_{2} \rightarrow \mathrm{O}_{4}^{+}+\mathrm{H}_{2} \mathrm{O}
$$$$
\mathrm{O}_{4}^{+}+\mathrm{H}_{2} \mathrm{O} \rightarrow \mathrm{O}_{2}+\mathrm{H}_{2} \mathrm{O}_{3}^{+}
$$$$
\mathrm{N}_{2}^{+}+\mathrm{H}_{2} \mathrm{O} \rightarrow \mathrm{N}_{2}+\mathrm{H}_{2} \mathrm{O}^{+}
$$$$
\mathrm{N}_{4}^{+}+\mathrm{H}_{2} \mathrm{O} \rightarrow 2 \mathrm{~N}_{2}+\mathrm{H}_{2} \mathrm{O}^{+}
$$$$
\mathrm{H}^{+}+\mathrm{O}_{2} \rightarrow \mathrm{H}+\mathrm{O}_{2}^{+}
$$$$
\mathrm{H}^{+}+\mathrm{H}_{2} \mathrm{O} \rightarrow \mathrm{H}+\mathrm{H}_{2} \mathrm{O}^{+}
$$$$
\mathrm{H}^{-}+\mathrm{H}_{2} \mathrm{O} \rightarrow \mathrm{OH}^{-}+\mathrm{H}_{2}
$$$$
\mathrm{H}_{2}^{+}+\mathrm{He} \rightarrow \mathrm{HeH}^{+}+\mathrm{H}
$$$$
\mathrm{H}_{2}^{+}+\mathrm{O}_{2} \rightarrow \mathrm{O}_{2}^{+}+\mathrm{H}_{2}
$$$$
\mathrm{H}_{2}^{+}+\mathrm{H}_{2} \mathrm{O} \rightarrow \mathrm{H}_{2} \mathrm{O}^{+}+\mathrm{H}_{2}
$$$$
\mathrm{H}_{2}^{+}+\mathrm{H}_{2} \mathrm{O} \rightarrow \mathrm{H}_{3} \mathrm{O}^{+}+\mathrm{H}
$$$$
\mathrm{O}^{-}+\mathrm{H}_{2} \mathrm{O} \rightarrow \mathrm{OH}^{-}+\mathrm{OH}
$$$$
\mathrm{OH}^{+}+\mathrm{O} \rightarrow \mathrm{O}_{2}^{+}+\mathrm{H}
$$$$
\mathrm{OH}^{+}+\mathrm{O}_{2} \rightarrow \mathrm{O}_{2}^{+}+\mathrm{OH}
$$$$
\mathrm{OH}^{+}+\mathrm{H}_{2} \mathrm{O} \rightarrow \mathrm{H}_{2} \mathrm{O}^{+}+\mathrm{OH}
$$$$
\mathrm{OH}^{+}+\mathrm{H}_{2} \mathrm{O} \rightarrow \mathrm{H}_{3} \mathrm{O}^{+}+\mathrm{O}
$$$$
\mathrm{H}_{2} \mathrm{O}^{+}+\mathrm{H}_{2} \mathrm{O} \rightarrow \mathrm{H}_{3} \mathrm{O}^{+}+\mathrm{OH}
$$$$
\mathrm{H}_{2} \mathrm{O}_{3}^{+}+\mathrm{H}_{2} \mathrm{O} \rightarrow \mathrm{H}_{4} \mathrm{O}_{2}^{+}+\mathrm{O}_{2}
$$$$
\mathrm{H}_{2} \mathrm{O}_{3}^{+}+\mathrm{H}_{2} \mathrm{O} \rightarrow \mathrm{H}_{3} \mathrm{O}^{+}+\mathrm{OH}+\mathrm{O}_{2}
$$$$
\mathrm{H}_{4} \mathrm{O}_{2}^{+}+\mathrm{H}_{2} \mathrm{O} \rightarrow \mathrm{H}_{5} \mathrm{O}_{2}^{+}+\mathrm{OH}
$$$$
\mathrm{H}_{3} \mathrm{O}^{+}+\mathrm{H}_{2} \mathrm{O}+M \rightarrow \mathrm{H}_{5} \mathrm{O}_{2}^{+}+M
$$

$2.08 \times 10^{-13} T_{e}^{-0.76} \exp \left(-6.9 / T_{e}\right)$

$2 \times 10^{-16} T_{e}^{1.78} \exp \left(-13.8 / T_{e}\right) \quad 13.8$

$3.1 \times 10^{-15} 0$

$2.36 \times 10^{-15} \quad 0$

$3.1 \times 10^{-17} \quad 0$

$3 \times 10^{-43}$

$1.4 \times 10^{-41}$

$1.57 \times 10^{-16} T_{e}^{-0.55}$

$2.7 \times 10^{-16} T_{e}^{-0.5}$

$1.62 \times 10^{-12} T_{e}^{-0.15}$

$9.6 \times 10^{-13} T_{e}^{-0.2}$

$2.24 \times 10^{-12} T_{e}^{-0.08}$
$3.6 \times 10^{-12}$

$4 \times 10^{-12}$

$4 \times 10^{-12}$

$4 \times 10^{-12}$

$4 \times 10^{-12}$

$4 \times 10^{-12}$

$8 \times 10^{-18}\left(T_{g} / 300\right)^{0.5}$

$1.2 \times 10^{-15}$

$2.04 \times 10^{-16}$

$2.86 \times 10^{-16}$

$6.05 \times 10^{-17}$

$9.1 \times 10^{-16}$

$4.3 \times 10^{-16}$

$1.3 \times 10^{-16}$

$2.1 \times 10^{-16}$

$2.1 \times 10^{-16}$

$2.1 \times 10^{-16}$

$2.1 \times 10^{-16}$

$2.6 \times 10^{-40}\left(T_{g} / 300\right)^{-4}$

$2.6 \times 10^{-40}\left(T_{g} / 300\right)^{-4}$

$2.6 \times 10^{-40}\left(T_{g} / 300\right)^{-4}$

$1.5 \times 10^{-40}\left(T_{g} / 300\right)^{2}$

$3.3 \times 10^{-16}$

$2 \times 10^{-16} \exp \left(-2300 / T_{g}\right)$

$1.7 \times 10^{-15}$

$3 \times 10^{-15}$

$2.4 \times 10^{-15}$

$2 \times 10^{-15}$

$6.9 \times 10^{-15}$

$3.8 \times 10^{-15}$

$1.3 \times 10^{-16}$

$8 \times 10^{-16}$

$3.9 \times 10^{-15}$

$3.4 \times 10^{-15}$

$1.4 \times 10^{-15}$

$7.1 \times 10^{-16}$

$3.8 \times 10^{-16}$

$1.5 \times 10^{-15}$

$1.3 \times 10^{-15}$

$1.85 \times 10^{-15}$

$1 \times 10^{-15}$

$3 \times 10^{-16}$

$1.4 \times 10^{-15}$

$3.2 \times 10^{-39}\left(T_{g} / 300\right)^{-4}$
[93]

[93]

[79]

[79]

[79]

[94]

[81]

[95]

[95]

[96]

[96]

[97]

[97]

[98]

[98]

[98]

[98]

[98]

[51]

[99]

[66]

[66]

[66]

[66]

[100]

[101]

[51]

[51]

[51]

[51]

[96]

[102]

[102]

[104]

[66]

[66]

[66]

[66]

[66]

[66]

[66]

[105]

[66]

[81]

[106]

[107]

[81]

[96]

[105]

[96]

[104] 
$\mathrm{H}_{5} \mathrm{O}_{2}^{+}+\mathrm{H}_{2} \mathrm{O}+M \rightarrow \mathrm{H}_{7} \mathrm{O}_{3}^{+}+M$

$\mathrm{H}_{7} \mathrm{O}_{3}^{+}+\mathrm{H}_{2} \mathrm{O}+M \rightarrow \mathrm{H}_{9} \mathrm{O}_{4}^{+}+M$

$\mathrm{H}_{9} \mathrm{O}_{4}^{+}+M \rightarrow \mathrm{H}_{7} \mathrm{O}_{3}^{+}+\mathrm{H}_{2} \mathrm{O}+M$

$\mathrm{H}_{9} \mathrm{O}_{4}^{+}+\mathrm{H}_{2} \mathrm{O}+M \rightarrow \mathrm{H}_{11} \mathrm{O}_{5}^{+}+M$

$$
\mathrm{H}_{11} \mathrm{O}_{5}^{+}+M \rightarrow \mathrm{H}_{9} \mathrm{O}_{4}^{+}+\mathrm{H}_{2} \mathrm{O}+M
$$$$
\mathrm{H}_{11} \mathrm{O}_{5}^{+}+\mathrm{H}_{2} \mathrm{O}+M \rightarrow \mathrm{H}_{13} \mathrm{O}_{6}^{+}+M
$$$$
\mathrm{H}_{13} \mathrm{O}_{6}^{+}+M \rightarrow \mathrm{H}_{11} \mathrm{O}_{5}^{+}+\mathrm{H}_{2} \mathrm{O}+M
$$$$
\mathrm{H}_{13} \mathrm{O}_{6}^{+}+\mathrm{H}_{2} \mathrm{O}+M \rightarrow \mathrm{H}_{15} \mathrm{O}_{7}^{+}+M
$$$$
\mathrm{H}_{15} \mathrm{O}_{7}^{+}+M \rightarrow \mathrm{H}_{13} \mathrm{O}_{6}^{+}+\mathrm{H}_{2} \mathrm{O}+M
$$$$
\mathrm{H}_{15} \mathrm{O}_{7}^{+}+\mathrm{H}_{2} \mathrm{O}+M \rightarrow \mathrm{H}_{17} \mathrm{O}_{8}^{+}+M
$$$$
\mathrm{H}_{17} \mathrm{O}_{8}^{+}+M \rightarrow \mathrm{H}_{15} \mathrm{O}_{7}^{+}+\mathrm{H}_{2} \mathrm{O}+M
$$$$
\mathrm{H}_{17} \mathrm{O}_{8}^{+}+\mathrm{H}_{2} \mathrm{O}+M \rightarrow \mathrm{H}_{19} \mathrm{O}_{9}^{+}+M
$$$$
\mathrm{H}_{19} \mathrm{O}_{9}^{+}+M \rightarrow \mathrm{H}_{17} \mathrm{O}_{8}^{+}+\mathrm{H}_{2} \mathrm{O}+M
$$$$
\mathrm{O}^{-}+\mathrm{H}_{2} \mathrm{O}+M \rightarrow \mathrm{H}_{2} \mathrm{O}_{2}^{-}+M
$$$$
\mathrm{OH}^{-}+\mathrm{H}_{2} \mathrm{O}+M \rightarrow \mathrm{H}_{3} \mathrm{O}_{2}^{-}+M
$$$$
\mathrm{H}_{2} \mathrm{O}_{2}^{-}+\mathrm{H}_{2} \mathrm{O} \rightarrow \mathrm{H}_{3} \mathrm{O}_{2}^{-}+\mathrm{OH}
$$$$
\mathrm{H}_{3} \mathrm{O}_{2}^{-}+\mathrm{H}_{2} \mathrm{O}+M \rightarrow \mathrm{H}_{5} \mathrm{O}_{3}^{-}+M
$$

$\mathrm{He}^{+}+\mathrm{OH}^{-}+M \rightarrow \mathrm{OH}+\mathrm{He}+M$

$\mathrm{He}_{2}^{+}+\mathrm{O}^{-}+M \rightarrow \mathrm{O}+2 \mathrm{He}+M$

$\mathrm{He}_{2}^{+}+\mathrm{OH}^{-}+M \rightarrow \mathrm{OH}+2 \mathrm{He}+M$

$$
\mathrm{He}_{2}^{+}+\mathrm{H}_{2} \mathrm{O}_{2}^{-}+M \rightarrow 2 \mathrm{He}+\mathrm{O}+\mathrm{H}_{2} \mathrm{O}+M
$$$$
\mathrm{He}_{2}^{+}+\mathrm{H}_{3} \mathrm{O}_{2}^{-}+M \rightarrow 2 \mathrm{He}+\mathrm{OH}+\mathrm{H}_{2} \mathrm{O}+M
$$

$\mathrm{He}_{2}^{+}+\mathrm{H}_{5} \mathrm{O}_{3}^{-}+M \rightarrow 2 \mathrm{He}+\mathrm{OH}+2 \mathrm{H}_{2} \mathrm{O}+M$

$$
\mathrm{O}_{2}^{+}+\mathrm{OH}^{-} \rightarrow \mathrm{O}_{2}+\mathrm{OH}
$$

$$
\begin{gathered}
\mathrm{O}_{2}^{+}+\mathrm{H}_{2} \mathrm{O}_{2}^{-}+M \rightarrow \mathrm{O}_{2}+\mathrm{O}+\mathrm{H}_{2} \mathrm{O}+M \\
\mathrm{O}_{2}^{+}+\mathrm{H}_{3} \mathrm{O}_{2}^{-}+M \rightarrow \mathrm{O}_{2}+\mathrm{OH}+\mathrm{H}_{2} \mathrm{O}+M \\
\mathrm{O}_{2}^{+}+\mathrm{H}_{5} \mathrm{O}_{3}^{-}+M \rightarrow \mathrm{O}_{2}+\mathrm{OH}+2 \mathrm{H}_{2} \mathrm{O}+M \\
\mathrm{OH}^{+}+\mathrm{O}^{-} \rightarrow \mathrm{HO}_{2} \\
\mathrm{OH}^{+}+\mathrm{O}_{2}^{-} \rightarrow \mathrm{OH}+\mathrm{O}_{2}
\end{gathered}
$$

$$
\mathrm{OH}^{+}+\mathrm{H}_{2} \mathrm{O}_{2}^{-}+M \rightarrow \mathrm{O}+\mathrm{OH}+2 \mathrm{H}_{2} \mathrm{O}+M
$$$$
\mathrm{OH}^{+}+\mathrm{H}_{5} \mathrm{O}_{3}^{-}+M \rightarrow 2 \mathrm{OH}+2 \mathrm{H}_{2} \mathrm{O}+M
$$$$
\mathrm{H}_{2} \mathrm{O}^{+}+\mathrm{O}^{-}+M \rightarrow \mathrm{O}+\mathrm{H}_{2} \mathrm{O}+M
$$$$
\mathrm{H}_{2} \mathrm{O}^{+}+\mathrm{OH}^{-}+M \rightarrow \mathrm{OH}+\mathrm{H}_{2} \mathrm{O}+M
$$$$
\mathrm{H}_{2} \mathrm{O}^{+}+\mathrm{H}_{2} \mathrm{O}_{2}^{-}+M \rightarrow \mathrm{O}+2 \mathrm{H}_{2} \mathrm{O}+M
$$$$
\mathrm{H}_{2} \mathrm{O}^{+}+\mathrm{H}_{3} \mathrm{O}_{2}^{-}+M \rightarrow \mathrm{OH}+2 \mathrm{H}_{2} \mathrm{O}+M
$$

$$
\mathrm{H}_{2} \mathrm{O}^{+}+\mathrm{H}_{5} \mathrm{O}_{3}^{-}+M \rightarrow \mathrm{OH}+3 \mathrm{H}_{2} \mathrm{O}+M
$$

$$
\mathrm{H}_{2} \mathrm{O}_{3}^{+}+\mathrm{O}^{-}+M \rightarrow \mathrm{H}_{2} \mathrm{O}+\mathrm{O}+\mathrm{O}_{2}+M
$$

$$
\mathrm{H}_{2} \mathrm{O}_{3}^{+}+\mathrm{O}_{2}^{-}+M \rightarrow \mathrm{H}_{2} \mathrm{O}+2 \mathrm{O}_{2}+M
$$

$$
\mathrm{H}_{2} \mathrm{O}_{3}^{+}+\mathrm{H}_{5} \mathrm{O}_{3}^{-}+M \rightarrow 3 \mathrm{H}_{2} \mathrm{O}+\mathrm{OH}+\mathrm{O}_{2}+M
$$

$$
\mathrm{H}_{9} \mathrm{O}_{4}^{+}+\mathrm{H}_{2} \mathrm{O}_{2}^{-}+M \rightarrow 5 \mathrm{H}_{2} \mathrm{O}+\mathrm{OH}+M
$$

$$
\mathrm{H}_{9} \mathrm{O}_{4}^{+}+\mathrm{H}_{5} \mathrm{O}_{3}^{-}+M \rightarrow 7 \mathrm{H}_{2} \mathrm{O}+M
$$$$
\mathrm{H}_{11} \mathrm{O}_{5}^{+}+\mathrm{H}_{2} \mathrm{O}_{2}^{-}+M \rightarrow \mathrm{OH}+6 \mathrm{H}_{2} \mathrm{O}+M
$$

$$
\mathrm{H}_{11} \mathrm{O}_{5}^{+}+\mathrm{H}_{5} \mathrm{O}_{3}^{-}+M \rightarrow 8 \mathrm{H}_{2} \mathrm{O}+M
$$$$
\mathrm{H}_{13} \mathrm{O}_{6}^{+}+\mathrm{H}_{2} \mathrm{O}_{2}^{-}+M \rightarrow \mathrm{OH}+7 \mathrm{H}_{2} \mathrm{O}+M
$$$$
\mathrm{H}_{13} \mathrm{O}_{6}^{+}+\mathrm{H}_{5} \mathrm{O}_{3}^{-}+M \rightarrow 9 \mathrm{H}_{2} \mathrm{O}+M
$$

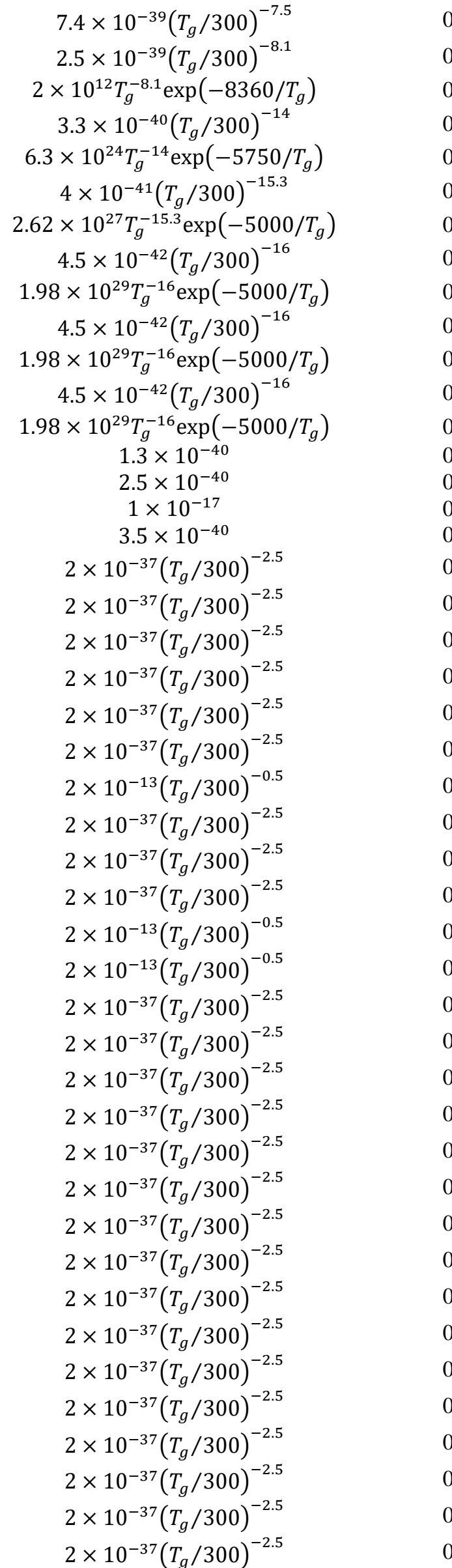




$$
\begin{gathered}
\mathrm{H}_{15} \mathrm{O}_{7}^{+}+\mathrm{H}_{2} \mathrm{O}_{2}^{-}+M \rightarrow \mathrm{OH}+8 \mathrm{H}_{2} \mathrm{O}+M \\
\mathrm{H}_{15} \mathrm{O}_{7}^{+}+\mathrm{H}_{5} \mathrm{O}_{3}^{-}+M \rightarrow 10 \mathrm{H}_{2} \mathrm{O}+M \\
\mathrm{H}_{17} \mathrm{O}_{8}^{+}+\mathrm{H}_{2} \mathrm{O}_{2}^{-}+M \rightarrow \mathrm{OH}+9 \mathrm{H}_{2} \mathrm{O}+M \\
\mathrm{H}_{17} \mathrm{O}_{8}^{+}+\mathrm{H}_{5} \mathrm{O}_{3}^{-}+M \rightarrow 11 \mathrm{H}_{2} \mathrm{O}+M
\end{gathered}
$$$$
\mathrm{H}_{19} \mathrm{O}_{9}^{+}+\mathrm{H}_{2} \mathrm{O}_{2}^{-}+M \rightarrow \mathrm{OH}+10 \mathrm{H}_{2} \mathrm{O}+M
$$$$
\mathrm{H}_{19} \mathrm{O}_{9}^{+}+\mathrm{H}_{5} \mathrm{O}_{3}^{-}+M \rightarrow 12 \mathrm{H}_{2} \mathrm{O}+M
$$$$
\mathrm{H}_{9} \mathrm{O}_{4}^{+}+\mathrm{O}^{-}+M \rightarrow 4 \mathrm{H}_{2} \mathrm{O}+\mathrm{OH}+M
$$$$
\mathrm{H}_{9} \mathrm{O}_{4}^{+}+\mathrm{O}_{2}^{-}+M \rightarrow 4 \mathrm{H}_{2} \mathrm{O}+\mathrm{O}_{2}+\mathrm{H}+M
$$$$
\mathrm{H}_{11} \mathrm{O}_{5}^{+}+\mathrm{O}^{-}+M \rightarrow 5 \mathrm{H}_{2} \mathrm{O}+\mathrm{OH}+M
$$$$
\mathrm{H}_{11} \mathrm{O}_{5}^{+}+\mathrm{O}_{2}^{-}+M \rightarrow 5 \mathrm{H}_{2} \mathrm{O}+\mathrm{O}_{2}+\mathrm{H}+M
$$$$
\mathrm{H}_{13} \mathrm{O}_{6}^{+}+\mathrm{O}^{-}+M \rightarrow 6 \mathrm{H}_{2} \mathrm{O}+\mathrm{OH}+M
$$$$
\mathrm{H}_{13} \mathrm{O}_{6}^{+}+\mathrm{O}_{2}^{-}+M \rightarrow 6 \mathrm{H}_{2} \mathrm{O}+\mathrm{O}_{2}+\mathrm{H}+M
$$$$
\mathrm{He}_{\mathrm{m}}+\mathrm{H} \rightarrow \mathrm{H}^{+}+\mathrm{He}+\mathrm{e}^{-}
$$$$
\mathrm{He}_{\mathrm{m}}+\mathrm{H}_{2} \rightarrow \mathrm{H}_{2}^{+}+\mathrm{He}+\mathrm{e}^{-}
$$$$
\mathrm{He}_{\mathrm{m}}+\mathrm{OH} \rightarrow \mathrm{OH}^{+}+\mathrm{He}+\mathrm{e}^{-}
$$$$
\mathrm{He}_{\mathrm{m}}+\mathrm{H}_{2} \mathrm{O} \rightarrow \mathrm{H}_{2} \mathrm{O}^{+}+\mathrm{He}+\mathrm{e}^{-}
$$$$
\mathrm{He}_{\mathrm{m}}+\mathrm{H}_{2} \mathrm{O} \rightarrow \mathrm{H}+\mathrm{OH}^{+}+\mathrm{He}+\mathrm{e}^{-}
$$$$
\mathrm{He}_{\mathrm{m}}+\mathrm{H}_{2} \mathrm{O} \rightarrow \mathrm{OH}+\mathrm{H}^{+}+\mathrm{He}+\mathrm{e}^{-}
$$$$
\mathrm{He}_{\mathrm{m}}+\mathrm{H}_{2} \mathrm{O} \rightarrow \mathrm{OH}+\mathrm{HeH}^{+}+\mathrm{e}^{-}
$$$$
\mathrm{He}_{\mathrm{m}}+\mathrm{H}_{2} \mathrm{O}_{2} \rightarrow \mathrm{He}+\mathrm{OH}^{+}+\mathrm{OH}+\mathrm{e}^{-}
$$$$
\mathrm{He}_{2}^{*}+\mathrm{H}_{2} \rightarrow \mathrm{H}_{2}^{+}+2 \mathrm{He}+\mathrm{e}^{-}
$$$$
\mathrm{He}_{2}^{*}+\mathrm{OH} \rightarrow \mathrm{OH}^{+}+2 \mathrm{He}+\mathrm{e}^{-}
$$$$
\mathrm{He}_{2}^{*}+\mathrm{H}_{2} \mathrm{O} \rightarrow \mathrm{H}_{2} \mathrm{O}^{+}+2 \mathrm{He}+\mathrm{e}^{-}
$$$$
\mathrm{He}_{2}^{*}+\mathrm{H}_{2} \mathrm{O} \rightarrow 2 \mathrm{He}+\mathrm{H}_{2} \mathrm{O}
$$$$
\mathrm{He}+\mathrm{OH}(\mathrm{A}) \rightarrow \mathrm{He}+\mathrm{OH}
$$$$
\mathrm{He}+\mathrm{H}+\mathrm{O}_{2} \rightarrow \mathrm{He}+\mathrm{HO}_{2}
$$$$
\mathrm{He}+\mathrm{H}+\mathrm{OH} \rightarrow \mathrm{He}+\mathrm{H}_{2} \mathrm{O}
$$$$
\mathrm{H}+\mathrm{O}_{3} \rightarrow \mathrm{OH}+\mathrm{O}_{2}
$$$$
\mathrm{H}+\mathrm{HO}_{2} \rightarrow \mathrm{H}_{2}+\mathrm{O}_{2}
$$$$
\mathrm{H}+\mathrm{HO}_{2} \rightarrow 2 \mathrm{OH}
$$$$
\mathrm{O}+\mathrm{OH} \rightarrow \mathrm{H}+\mathrm{O}_{2}
$$$$
\mathrm{O}+\mathrm{HO}_{2} \rightarrow \mathrm{OH}+\mathrm{O}_{2}
$$$$
\mathrm{O}\left({ }^{1} D\right)+\mathrm{H}_{2} \mathrm{O}_{2} \rightarrow \mathrm{H}_{2} \mathrm{O}+\mathrm{O}_{2}
$$$$
\mathrm{O}\left({ }^{1} D\right)+\mathrm{H}_{2} \mathrm{O} \rightarrow 2 \mathrm{OH}
$$$$
\mathrm{O}\left({ }^{1} D\right)+\mathrm{H}_{2} \mathrm{O} \rightarrow \mathrm{O}+\mathrm{H}_{2} \mathrm{O}
$$$$
\mathrm{O}_{2}(b)+\mathrm{H}_{2} \mathrm{O} \rightarrow \mathrm{O}_{2}(a)+\mathrm{H}_{2} \mathrm{O}
$$$$
2 \mathrm{OH} \rightarrow \mathrm{H}_{2} \mathrm{O}+\mathrm{O}
$$$$
2 \mathrm{OH} \rightarrow \mathrm{H}_{2} \mathrm{O}_{2}
$$$$
\mathrm{OH}+\mathrm{HO}_{2} \rightarrow \mathrm{O}_{2}+\mathrm{H}_{2} \mathrm{O}
$$$$
\mathrm{OH}+\mathrm{H}_{2} \mathrm{O}_{2} \rightarrow \mathrm{H}_{2} \mathrm{O}+\mathrm{HO}_{2}
$$$$
\mathrm{OH}(\mathrm{A})+\mathrm{H}_{2} \mathrm{O} \rightarrow \mathrm{H}_{2} \mathrm{O}+\mathrm{OH}
$$$$
\mathrm{OH}(\mathrm{A})+\mathrm{H}_{2} \mathrm{O}_{2} \rightarrow \mathrm{HO}_{2}+\mathrm{H}_{2} \mathrm{O}
$$

$$
2 \times 10^{-37}\left(T_{g} / 300\right)^{-2.5} \quad 0
$$$$
2 \times 10^{-37}\left(T_{g} / 300\right)^{-2.5} \quad 0
$$$$
2 \times 10^{-37}\left(T_{g} / 300\right)^{-2.5} \quad 0
$$$$
2 \times 10^{-37}\left(T_{g} / 300\right)^{-2.5} \quad 0
$$$$
2 \times 10^{-37}\left(T_{g} / 300\right)^{-2.5} \quad 0
$$$$
2 \times 10^{-37}\left(T_{g} / 300\right)^{-2.5} \quad 0
$$$$
2 \times 10^{-37}\left(T_{g} / 300\right)^{-2.5} \quad 0
$$$$
2 \times 10^{-37}\left(T_{g} / 300\right)^{-2.5} \quad 0
$$$$
2 \times 10^{-37}\left(T_{g} / 300\right)^{-2.5} \quad 0
$$$$
2 \times 10^{-37}\left(T_{g} / 300\right)^{-2.5} \quad 0
$$$$
2 \times 10^{-37}\left(T_{g} / 300\right)^{-2.5} \quad 0
$$$$
2 \times 10^{-37}\left(T_{g} / 300\right)^{-2.5} \quad 0
$$$$
1.1 \times 10^{-15}
$$$$
2.9 \times 10^{-17}
$$$$
7.8 \times 10^{-16}
$$$$
6.6 \times 10^{-16}
$$$$
1.5 \times 10^{-16}
$$$$
2.6 \times 10^{-17}
$$$$
8.5 \times 10^{-18}
$$$$
7.8 \times 10^{-16}
$$$$
2.2 \times 10^{-16}
$$$$
6 \times 10^{-16}
$$$$
6 \times 10^{-16}
$$$$
1.5 \times 10^{-21}
$$$$
1.5 \times 10^{-20}
$$
[101]

Note: ${ }^{a)} \mathrm{M}$ represents the background gases Helium atom, Nitrogen and Oxygen molecule. ${ }^{\text {b) }}$ Rate coefficients have units of $\mathrm{s}^{-1}, \mathrm{~m}^{3} \mathrm{~s}^{-1}, \mathrm{~m}^{6} \mathrm{~s}^{-1}$ for one, two and three body reactions respectively; $\mathrm{T}_{\mathrm{e}}$ has units of $\mathrm{eV}$; $\mathrm{T}_{\mathrm{g}}$ has units of $\mathrm{K}$. $f(\varepsilon)$ indicates the rate coefficient as a function of the mean electron energy calculated from the solution of Boltzmann equation. The reference indicates the database of the cross section used. ${ }^{\text {b) }}$ The cross sections are calculated by detailed balancing.

\section{References:}

[1] Große-Kreul S, Corbella C, von Keudell A, Ozkaya B and Grundmeier G 2013 
Surface Modification of Polypropylene (PP) by Argon Ions and UV Photons Plasma Process. Polym. 10 1110-9

[2] Chiper A and Borcia G 2013 Argon Versus Helium Dielectric Barrier Discharge for Surface Modification of Polypropylene and Poly(methyl methacrylate) Films Plasma Chem. Plasma Process. 33 553-68

[3] Yusupov M, Neyts E C, Simon P, Berdiyorov G, Snoeckx R, van Duin A C T and Bogaerts A 2014 Reactive molecular dynamics simulations of oxygen species in a liquid water layer of interest for plasma medicine J. Phys. D. Appl. Phys. 47025205

[4] Iza F, Kim G J, Lee S M, Lee J K, Walsh J L, Zhang Y T and Kong M G 2008 Microplasmas: Sources, Particle Kinetics, and Biomedical Applications Plasma Process. Polym. 5 322-44

[5] Kelly-Wintenberg K, Montie T C, Brickman C, Roth J R, Carr A K, Sorge K, Wadsworth L C and Tsai P P Y 1998 Room temperature sterilization of surfaces and fabrics with a One Atmosphere Uniform Glow Discharge Plasma J. Ind. Microbiol. Biotechnol. 20 69-74

[6] Laroussi M 2005 Low Temperature Plasma-Based Sterilization: Overview and Stateof-the-Art Plasma Process. Polym. 2 391-400

[7] van Gessel B, Brandenburg R and Bruggeman P 2013 Electron properties and air mixing in radio frequency driven argon plasma jets at atmospheric pressure Appl. Phys. Lett. 103064103

[8] Große-Kreul S, Corbella C and von Keudell A 2013 Chemical and Physical Sputtering of Polyethylene Terephthalate (PET) Plasma Process. Polym. 10 225-34

[9] Trunec D, Brablec A and Buchta J 2001 Atmospheric pressure glow discharge in neon J. Phys. D. Appl. Phys. 34 1697-9

[10] Trunec D, Brandenburg R, Michel P, Pasedag D and Navratil Z 2002 Spatiotemporally resolved emission spectroscopy of the atmospheric pressure glow discharge in neon Proc. Int. Symp. High Press. Low Temp. Plasma Chem.-HAKONE VIII p 63

[11] Ran J, Luo H and Wang X 2011 A dielectric barrier discharge in neon at atmospheric pressure J. Phys. D. Appl. Phys. 44335203

[12] Massines F, Rabehi A, Decomps P, Gadri R Ben, Ségur P and Mayoux C 1998 Experimental and theoretical study of a glow discharge at atmospheric pressure controlled by dielectric barrier J. Appl. Phys. 832950

[13] Nersisyan G and Graham W G 2004 Characterization of a dielectric barrier discharge operating in an open reactor with flowing helium Plasma Sources Sci. Technol. 13 $582-7$

[14] Navrátil Z, Brandenburg R, Trunec D, Brablec a, St'ahel P, Wagner H-E and Kopecký Z 2006 Comparative study of diffuse barrier discharges in neon and helium Plasma Sources Sci. Technol. 15 8-17

[15] Bogaczyk M, Wild R, Stollenwerk L and Wagner H-E 2012 Surface charge accumulation and discharge development in diffuse and filamentary barrier discharges operating in He, N 2 and mixtures J. Phys. D. Appl. Phys. 45465202

[16] Kogelschatz U 2003 No Title Plasma Chem. Plasma Process. 23 1-46

[17] Brandenburg R 2017 Dielectric barrier discharges: progress on plasma sources and on the understanding of regimes and single filaments Plasma Sources Sci. Technol. 26 053001 
[18] Nastuta A V, Topala I, Grigoras C, Pohoata V and Popa G 2011 Stimulation of wound healing by helium atmospheric pressure plasma treatment J. Phys. D. Appl. Phys. 44105204

[19] Keidar M 2015 Plasma for cancer treatment Plasma Sources Sci. Technol. 24033001

[20] Lazzaroni C, Chabert P, Lieberman M A, Lichtenberg A J and Leblanc A 2012 Analytical-numerical global model of atmospheric-pressure radio-frequency capacitive discharges Plasma Sources Sci. Technol. 21035013

[21] Abd-Allah Z, Sawtell D A G, McKay K, West G T, Kelly P J and Bradley J W 2015 Mass spectrometric investigation of the ionic species in a dielectric barrier discharge operating in helium-water vapour mixtures J. Phys. D. Appl. Phys. 48085202

[22] McKay K, Donaghy D, He F and Bradley J W 2017 Studying Townsend and glow modes in an atmospheric-pressure DBD using mass spectrometry Plasma Sources Sci. Technol. 27015002

[23] Gorbanev Y, O'Connell D and Chechik V 2016 Non-Thermal Plasma in Contact with Water: The Origin of Species Chem. - A Eur. J. 22 3496-505

[24] Bruggeman P, Iza F, Lauwers D and Gonzalvo Y A 2010 Mass spectrometry study of positive and negative ions in a capacitively coupled atmospheric pressure RF excited glow discharge in He-water mixtures J. Phys. D. Appl. Phys. 43012003

[25] Bruggeman P J, Kushner M J, Locke B R, Gardeniers J G E, Graham W G, Graves D B, Hofman-Caris R C H M, Maric D, Reid J P, Ceriani E, Fernandez Rivas D, Foster J E, Garrick S C, Gorbanev Y, Hamaguchi S, Iza F, Jablonowski H, Klimova E, Kolb J, Krcma F, Lukes P, Machala Z, Marinov I, Mariotti D, Mededovic Thagard S, Minakata D, Neyts E C, Pawlat J, Petrovic Z L, Pflieger R, Reuter S, Schram D C, Schröter S, Shiraiwa M, Tarabová B, Tsai P A, Verlet J R R, von Woedtke T, Wilson $\mathrm{K}$ R, Yasui $\mathrm{K}$ and Zvereva G 2016 Plasma-liquid interactions: a review and roadmap Plasma Sources Sci. Technol. 25053002

[26] Kawamura E, Lieberman M A and Lichtenberg A J 2016 Standing striations due to ionization instability in atmospheric pressure $\mathrm{He} / \mathrm{H} 2 \mathrm{O}$ radio frequency capacitive discharges Plasma Sources Sci. Technol. 25054009

[27] Kawamura E, Lieberman M A and Lichtenberg A J 2018 Ionization instability induced striations in low frequency and pulsed $\mathrm{He} / \mathrm{H} 2 \mathrm{O}$ atmospheric pressure plasmas Phys. Plasmas 25013535

[28] Ding K, Lieberman M A and Lichtenberg A J 2014 Hybrid model of neutral diffusion, sheaths, and the $\alpha$ to $\gamma$ transition in an atmospheric pressure $\mathrm{He} / \mathrm{H} 2 \mathrm{O}$ bounded rf discharge J. Phys. D. Appl. Phys. 47305203

[29] Kawamura E, Lieberman M a, Lichtenberg a J, Chabert P and Lazzaroni C 2014 Particle-in-cell and global simulations of $\alpha$ to $\gamma$ transition in atmospheric pressure Penning-dominated capacitive discharges Plasma Sources Sci. Technol. 23035014

[30] Kawamura E, Lieberman M A and Lichtenberg A J 2017 Ionization instability induced striations in atmospheric pressure $\mathrm{He} / \mathrm{H} 2 \mathrm{O}$ RF and DC discharges J. Phys. D. Appl. Phys. 50145204

[31] Tavant A and Lieberman M A 2016 Hybrid global model of water cluster ions in atmospheric pressure Ar/ H 2 O RF capacitive discharges J. Phys. D. Appl. Phys. 49 465201

[32] Große-Kreul S, Hübner S, Benedikt J and von Keudell A 2016 Sampling of ions at atmospheric pressure: ion transmission and ion energy studied by simulation and experiment Eur. Phys. J. D 70103 
[33] Große-Kreul S, Hübner S, Schneider S, von Keudell A and Benedikt J 2016 Methods of gas purification and effect on the ion composition in an RF atmospheric pressure plasma jet investigated by mass spectrometry EPJ Tech. Instrum. 36

[34] Chiper A S, B.-Simiand N, Jorand F, Pasquiers S, Popa G and Postel C 2006 Influence of water vapour on acetaldehyde removal efficiency by DBD $J$. Optoelectron. Adv. Mater. 8 208-11

[35] Murakami T, Niemi K, Gans T, O’Connell D and Graham W G 2013 Chemical kinetics and reactive species in atmospheric pressure helium-oxygen plasmas with humid-air impurities Plasma Sources Sci. Technol. 22015003

[36] Murakami T, Niemi K, Gans T, O’Connell D and Graham W G 2013 Interacting kinetics of neutral and ionic species in an atmospheric-pressure helium-oxygen plasma with humid air impurities Plasma Sources Sci. Technol. 22045010

[37] Murakami T, Niemi K, Gans T, O’Connell D and Graham W G 2014 Afterglow chemistry of atmospheric-pressure helium-oxygen plasmas with humid air impurity Plasma Sources Sci. Technol. 23025005

[38] Liu D X, Bruggeman P, Iza F, Rong M Z and Kong M G 2010 Global model of lowtemperature atmospheric-pressure He + H 2 O plasmas Plasma Sources Sci. Technol. 19025018

[39] Liu D X, Iza F, Wang X H, Kong M G and Rong M Z $2011 \mathrm{He}+\mathrm{O} 2+\mathrm{H} 2 \mathrm{O}$ plasmas as a source of reactive oxygen species Appl. Phys. Lett. 98221501

[40] Schröter S, Gibson A R, Kushner M J, Gans T and O'Connell D 2018 Numerical study of the influence of surface reaction probabilities on reactive species in an $\mathrm{rf}$ atmospheric pressure plasma containing humidity Plasma Phys. Control. Fusion 60 014035

[41] Hodoroaba B, Gerber I C, Ciubotaru D, Mihaila I, Dobromir M, Pohoata V and Topala I 2018 Carbon "fluffy" aggregates produced by helium-hydrocarbon highpressure plasmas as analogues to interstellar dust Mon. Not. R. Astron. Soc. $4812841-$ 50

[42] Chelouah A, Marode E, Hartmann G and Achat S 1994 A new method for temperature evaluation in a nitrogen discharge J. Phys. D. Appl. Phys. 27 940-5

[43] Chiper A S, Aniţa V, Agheorghiesei C, Pohoaţa V, Aniţa M and Popa G 2004 Spectroscopic Diagnostics for a DBD Plasma in He/Air and He/N2 Gas Mixtures Plasma Process. Polym. 157-62

[44] Hagelaar G J M and Pitchford L C 2005 Solving the Boltzmann equation to obtain electron transport coefficients and rate coefficients for fluid models Plasma Sources Sci. Technol. 14 722-33

[45] Hagelaar G J M, Hoog F J De and Kroesen G M W 2000 t 1, 0, 62 1452-4

[46] Lazarou C, Belmonte T, Chiper A S S and Georghiou G E E 2016 Numerical modelling of the effect of dry air traces in a helium parallel plate dielectric barrier discharge Plasma Sources Sci. Technol. 25055023

[47] Viehland L A and Kirkpatrick C C 1995 Relating ion/neutral reaction rate coefficients and cross-sections by accessing a database for ion transport properties Int. J. Mass Spectrom. Ion Process. 149-150 555-71

[48] Neufeld P D 1972 Empirical Equations to Calculate 16 of the Transport Collision Integrals $\Omega(1, \mathrm{~s}) J$. Chem. Phys. 571100

[49] Brokaw R S 1969 Predicting Transport Properties of Dilute Gases Ind. Eng. Chem. 
Process Des. Dev. 8 240-53

[50] Yuan X and Raja L L 2003 Computational study of capacitively coupled highpressure glow discharges in helium IEEE Trans. Plasma Sci. 31 495-503

[51] Liu D-X, Rong M-Z, Wang X-H, Iza F, Kong M G and Bruggeman P 2010 Main Species and Physicochemical Processes in Cold Atmospheric-pressure $\mathrm{He}+\mathrm{O} 2$ Plasmas Plasma Process. Polym. 7 846-65

[52] Babaeva N Y and Kushner M J 2013 Reactive fluxes delivered by dielectric barrier discharge filaments to slightly wounded skin J. Phys. D. Appl. Phys. $\mathbf{4 6} 025401$

[53] Zhang P and Kortshagen U 2006 Two-dimensional numerical study of atmospheric pressure glows in helium with impurities J. Phys. D. Appl. Phys. 39 153-63

[54] Bogaczyk M, Nemschokmichal S, Wild R, Stollenwerk L, Brandenburg R, Meichsner J and Wagner H-E 2012 Development of Barrier Discharges: Operation Modes and Structure Formation Contrib. to Plasma Phys. 52 847-55

[55] COMSOL Multiphysics® v. 4.4. www.comsol.com. COMSOL AB, Stockholm, Sweden.

[56] http://www.pardiso-project.org/

[57] Massines F, Gherardi N, Naudé N and Ségur P 2005 Glow and Townsend dielectric barrier discharge in various atmosphere Plasma Phys. Control. Fusion 47 B577-88

[58] Martens T, Bogaerts A, Brok W J M and van Dijk J 2010 The influence of impurities on the performance of the dielectric barrier discharge Appl. Phys. Lett. 96091501

[59] Morgan database, www.lxcat.net, retrieved on September 25, 2015

[60] Lieberman M a 2015 Analytical model of atmospheric pressure, helium/trace gas radio-frequency capacitive Penning discharges Plasma Sources Sci. Technol. 24 025009

[61] Deloche R, Monchicourt P, Cheret M and Lambert F 1976 High-pressure helium afterglow at room temperature Phys. Rev. A 13 1140-76

[62] Stevefelt J 1982 Reaction kinetics of a high pressure helium fast discharge afterglow J. Chem. Phys. 764006

[63] Konstantinovskii R S, Shibkov V M and Shibkova L V 2005 Effect of a Gas Discharge on the Ignition in the Hydrogen - Oxygen System 46 821-34

[64] Wang Q, Economou D J and Donnelly V M 2006 Simulation of a direct current microplasma discharge in helium at atmospheric pressure J. Appl. Phys. 100023301

[65] Golubovskii Y B, Maiorov V A, Behnke J and Behnke J F 2003 Modelling of the homogeneous barrier discharge in helium at atmospheric pressure J. Phys. D. Appl. Phys. 36 39-49

[66] Millar T J, Farquhar P R A and Willacy K 1997 The UMIST database for astrochemistry 1995185 139-85

[67] IST-Lisbon database, www.lxcat.net, retrieved on September 25, 2015

[68] Castillo M, Méndez I, Islyaikin A M, Herrero V J and Tanarro I 2005 Low-pressure DC air plasmas. investigation of neutral and ion chemistry. J. Phys. Chem. A 109 6255-63

[69] Sommerer T J and Kushner M J 1992 Numerical investigation of the kinetics and chemistry of rf glow discharge plasmas sustained in $\mathrm{He}, \mathrm{N} 2, \mathrm{O} 2, \mathrm{He} / \mathrm{N} 2 / \mathrm{O} 2$, $\mathrm{He} / \mathrm{CF} 4 / \mathrm{O} 2$, and $\mathrm{SiH} 4 / \mathrm{NH} 3$ using a Monte Carlo-fluid hybrid model J. Appl. Phys. 71 
1654

[70] Raja L L 2003 Computational study of capacitively coupled high-pressure glow discharges in helium IEEE Trans. Plasma Sci. 31 495-503

[71] Kossyi I A, Kostinsky A Y, Matveyev A A and Silakov V P 1992 Kinetic scheme of the non-equilibrium discharge in nitrogen-oxygen mixtures Plasma Sources Sci. Technol. 1 207-20

[72] Tochikubo F, Uchida S, Yasui H and Sato K 2009 Numerical Simulation of NO Oxidation in Dielectric Barrier Discharge with Microdischarge Formation Jpn. J. Appl. Phys. 48076507

[73] Capitelli M, Ferreira C M, Gordiets B F and Osipov A I 2000 Plasma Kinetics in Atmospheric Gases vol 31 (Berlin, Heidelberg: Springer Berlin Heidelberg)

[74] Margot J, Petrov G M, Matte J P, Pe I, Sadi T, Hubert J, Tran K C, Alves L L, Loureiro J, Ferreira C M and Guerra V 2000 Numerical Modeling of a $\mathrm{He}-\mathrm{N} 2$ Capillary Surface' re $\mathbf{2 0}$

[75] Pouvesle J M 1982 Modeling of the charge transfer afterglow excited by intense electrical discharges in high pressure helium nitrogen mixtures J. Chem. Phys. 77817

[76] Lazarou C, Koukounis D, Chiper A S, Costin C, Topala I and Georghiou G E 2015 Numerical modeling of the effect of the level of nitrogen impurities in a helium parallel plate dielectric barrier discharge Plasma Sources Sci. Technol. 24035012

[77] TRINITI database, www.lxcat.net, retrieved on September 25, 2015

[78] Morgan database, www.lxcat.net, retrieved on August 3, 2016.

[79] Soloshenko I A, Tsiolko V V, Pogulay S S, Terent'yeva A G, Bazhenov V Y, Shchedrin A I, Ryabtsev A V and Kuzmichev A I 2007 The component content of active particles in a plasma-chemical reactor based on volume barrier discharge Plasma Sources Sci. Technol. 16 56-66

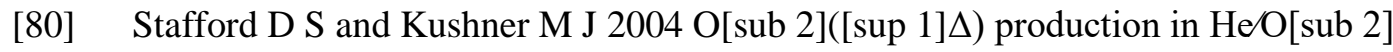
mixtures in flowing low pressure plasmas J. Appl. Phys. 962451

[81] Gordillo-Vázquez F J 2008 Air plasma kinetics under the influence of sprites J. Phys. D. Appl. Phys. 41234016

[82] Park G Y, Hong Y J, Lee H W, Sim J Y and Lee J K 2010 A Global Model for the Identification of the Dominant Reactions for Atomic Oxygen in He/O 2 AtmosphericPressure Plasmas Plasma Process. Polym. 7 281-7

[83] Atkinson R, Baulch D L, Cox R A, Hampson R F, Kerr J A, Rossi M J and Troe J 1997 Evaluated Kinetic, Photochemical and Heterogeneous Data for Atmospheric Chemistry: Supplement V. IUPAC Subcommittee on Gas Kinetic Data Evaluation for Atmospheric Chemistry J. Phys. Chem. Ref. Data 26521

[84] Stalder K R, Vidmar R J, Nersisyan G and Graham W G 2006 Modeling the chemical kinetics of high-pressure glow discharges in mixtures of helium with real air J. Appl. Phys. 99093301

[85] Good A 1975 Third-order ion-molecule clustering reactions Chem. Rev. 75 561-83

[86] Niemi K, Waskoenig J, Sadeghi N, Gans T and O'Connell D 2011 The role of helium metastable states in radio-frequency driven helium-oxygen atmospheric pressure plasma jets: measurement and numerical simulation Plasma Sources Sci. Technol. 20 055005

[87] Cardoso R P, Belmonte T, Henrion G and Sadeghi N 2006 Influence of trace oxygen 
on $\mathrm{He}(23 \mathrm{~S})$ density in a $\mathrm{He}-\mathrm{O} 2$ microwave discharge at atmospheric pressure: behaviour of the time afterglow J. Phys. D. Appl. Phys. 39 4178-85

[88] Lazarou C, Anastassiou C, Topala I, Chiper A S, Mihaila I, Pohoata V and Georghiou G E 2018 Numerical simulation of capillary helium and helium-oxygen atmospheric pressure plasma jets: propagation dynamics and interaction with dielectric Plasma Sources Sci. Technol. 27105007

[89] Kelly S and Turner M M 2013 Atomic oxygen patterning from a biomedical needleplasma source J. Appl. Phys. 114123301

[90] Brandenburg R, Maiorov V A, Golubovskii Y B, Wagner H-E, Behnke J and Behnke J F 2005 Diffuse barrier discharges in nitrogen with small admixtures of oxygen: discharge mechanism and transition to the filamentary regime J. Phys. D. Appl. Phys. 38 2187-97

[91] Yousfi M and Benabdessadok M D 1996 Boltzmann equation analysis of electronmolecule collision cross sections in water vapor and ammonia J. Appl. Phys. 806619

[92] Itikawa database, www.lxcat.net, retrieved on August 3, 2016.

[93] Riahi R, Teulet P, Ben Lakhdar Z and Gleizes A 2006 Cross-section and rate coefficient calculation for electron impact excitation, ionisation and dissociation of $\mathrm{H} 2$ and $\mathrm{OH}$ molecules Eur. Phys. J. D $40223-30$

[94] Axford S D T and Hayhurst A N 1996 Mass Spectrometric Sampling of Negative Ions from Flames of Hydrogen and Oxygen: The Kinetics of Electron Attachment and Detachment in Hot Mixtures of HFormulaO, OFormula, OH and HOFormula Proc. $R$. Soc. A Math. Phys. Eng. Sci. 452 1007-33

[95] Nandi D, Krishnakumar E, Rosa A, Schmidt W-F and Illenberger E 2003 Dissociative electron attachment to $\mathrm{H} 2 \mathrm{O} 2$ : a very effective source for $\mathrm{OH}$ and $\mathrm{OH}^{-}$generation Chem. Phys. Lett. 373 454-9

[96] Bortner M H and Baurer T 1979 Defense Nuclear Agency Reaction Rate Handbook (Section 24 Revision No. 7, March 1978, NTIS AD-7636 99, 1979)

[97] Huang C-M, Whitaker M, Biondi M A and Johnsen R 1978 Electron-temperature dependence of recombination of electrons with $\mathrm{H} 3 \mathrm{O}+\cdot(\mathrm{H} 2 \mathrm{O})$ n-series ions Phys. Rev. A 18 64-7

[98] Brian J 1990 The dissociative recombination of molecular ions Phys. Rep. 186 21548

[99] Dunkin D B 1970 Rate Constants for the Thermal Energy Reactions of H-. with O2, NO, CO, and N2O J. Chem. Phys. 53987

[100] Sanders R A and Muschlitz E E 1977 Chemiionization and secondary ion reactions in H2O and D2O Int. J. Mass Spectrom. Ion Phys. 23 99-108

[101] Binns W R and Ahl J L 1978 Excitation and quenching reactions in E-beam excited $\mathrm{He} / \mathrm{H} 2 \mathrm{O}$ and $\mathrm{He} / \mathrm{CH} 3 \mathrm{CN}$ systems J. Chem. Phys. 68538

[102] Hamden M 1989 Gas Phase Ion-Molecule Reaction Rate Constants Through 1986. Yasumasa Ikezoe, Shingo Matsuoka, Masahiro Takebe and Albert Viggiano (eds). Maruzen Company Ltd, Tokyo. 1987. (viii) + 244 pp. US\$150.00 Rapid Commun. Mass Spectrom. 3 iii - iii

[103] Vidmar R J and Stalder K R 2004 AFOSR Final Performance Report. Computations of the power to sustain plasma in air with relevance to aerospace technology. Final report prepared for Air Force Office of Scientific Research (No:

AFRISRARRE040123. Contact No. F49620-01-0414) 
[104] Sieck L W, Heron J T and Green D S 2000 Chemical Kinetics Database and Predictive Schemes for Humid Air Plasma Chemistry. Part I: Positive Ion-Molecule Reactions Plasma Chem. Plasma Process. 20 235-58

[105] Ferguson E E 1973 Rate constants of thermal energy binary ion-molecule reactions of aeronomic interest At. Data Nucl. Data Tables 12 159-78

[106] Eichwald O, Yousfi M, Hennad A and Benabdessadok M D 1997 Coupling of chemical kinetics, gas dynamics, and charged particle kinetics models for the analysis of NO reduction from flue gases J. Appl. Phys. 824781

[107] Jianli Z, Juncheng Z, Ji S, Hongchen G, Xiangsheng W and Weimin G 2009 Scale-Up Synthesis of Hydrogen Peroxide from H 2 /O 2 with Multiple Parallel DBD Tubes Plasma Sci. Technol. 11 181-6

[108] Fritzenwallner J and Kopp E 1998 Model calculations of the negative ion chemistry in the mesosphere with special emphasis on the chlorine species and the formation of cluster ions Adv. Sp. Res. 21 891-4

[109] Kushner M J 1999 Strategies for Rapidly Developing Plasma Chemistry Models Bull. Am. Phys. Soc. 4463

[110] Hagelaar G J M, Kroesen G M W, van Slooten U and Schreuders H 2000 Modeling of the microdischarges in plasma addressed liquid crystal displays J. Appl. Phys. 882252

[111] Park G, Lee H, Kim G and Lee J K 2008 Global Model of He/O 2 and Ar/O 2 Atmospheric Pressure Glow Discharges Plasma Process. Polym. 5 569-76

[112] Takao S, Kogoma M, Oka T, Imamura M and Arai S 1980 Optical absorption spectra

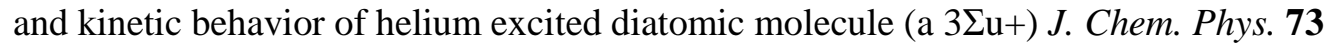
148

[113] Ricard A, Décomps P and Massines F 1999 Kinetics of radiative species in helium pulsed discharge at atmospheric pressure Surf. Coatings Technol. 112 1-4

[114] GRI-MECH 3 Reaction Rate Database. http://www.me.berkeley.edu/gri-mech/

[115] Tsang W and Hampson R F 1986 Chemical Kinetic Data Base for Combustion Chemistry. Part I. Methane and Related Compounds J. Phys. Chem. Ref. Data 151087

[116] NIST chemical kinetic database. http://kinetics.nist.gov/kinetics/index.jsp

[117] Dunlea E J, Talukdar R K and Ravishankara A R 2005 Kinetic Studies of the Reactions of O 2 (b $1 \Sigma \mathrm{g}+$ ) with Several Atmospheric Molecules J. Phys. Chem. A $1093912-20$

[118] Koike T and Morinaga K 1982 Further studies of the rate constant for chemical excitation of OH in shock waves. Bull. Chem. Soc. Jpn. 55 52-4

[119] Deng L, Shi W, Yang H, Sha G and Zhang C 2004 Improved method for measuring absolute $\mathrm{O} 2(\mathrm{a} 1 \Delta \mathrm{g})$ concentration by $\mathrm{O} 2(\mathrm{a} 1 \Delta \mathrm{g} \rightarrow \mathrm{X} 3 \Sigma-\mathrm{g})$ IR radiation Rev. Sci. Instrum. 754455 